\title{
Structured Model-Based Analysis and Control of the Hyaluronic Acid Fermentation by Streptococcus zooepidemicus: Physiological Implications of Glucose and Complex-Nitrogen-Limited Growth
}

\author{
M. J . Cooney, ${ }^{* \dagger}$ L.-T. Goh, ${ }^{\ddagger}$ P. L. Lee, ${ }^{\dagger}$ and M. R. J ohns ${ }^{\ddagger}$
}

School of Engineering, Murdoch University, WA 6150, Australia, and Department of Chemical Engineering, The University of Queensland, Brisbane, QId 4072, Australia

\begin{abstract}
The hyaluronic acid (HA) fermentation by Streptococcus zooepi demicus under anaerobic and aerated conditions in glucose-complex media was well described by a structured, two-compartment model. The two-compartment model framework was found to be robust, easily adaptable, and able to predict the transient consumption of substrates and formation of products. Aerobic culture produced a substantially higher concentration of HA than an equivalent anaerobic culture; however biomass-specific growth rate and yield were lower due to partial inhibition by hydrogen peroxide. The model was then used to investigate the physiological implications of glucose and complexnitrogen-limited growth on the anaerobic production of hyal uronic acid (HA). Glucoselimited growth agreed well with model predictions, although the HA molecular weight was lower than expected even though the absolute HA concentration remained unaffected. Heterofermentative growth was also observed for growth rates below 0.1 $\mathrm{h}^{-1}$. Despite a comparatively lower specific growth rate, the biomass yield was higher; however the metabolic shift did not significantly affect HA production. For complexnitrogen-limited growth, diauxic growth on complex-nitrogen (yeast extract) was observed and explained by partitioning the array of nitrogen components into two distinct but homogeneous pools. While nitrogen-limited growth was found to increase the HA to biomass yield, likethat observed under glucoselimited growth, the resulting HA molecular weight was reduced.
\end{abstract}

\section{Introduction}

Hyaluronic acid (HA) is a naturally occurring high molecular weight mucopolysacharide that exists naturally in humans. Principle uses of HA are in the biomedical field, such as ophthalmic and orthopaedic surgery $(1,2)$. Recently, several developmental collaborations and emerging applications have transformed the HA market into a billion dollar (US) per year industry. For example, several US companies such as Genzyme and Biomatrix have initiated multi-million dollar distribution contracts for new and emerging HA-based products such as viscosupplementation treatments, whose market is estimated to be worth 500 million dollars (US) per year (2).

Commercially, HA is produced through extraction from rooster combs or via fermentation, since the HA produced from these sources is chemically identical (e.g., same chemical structure but can be of different $\mathrm{Mw}$ ) to that found in humans (3). The fermentation process, however, has become increasingly attractive for large-scale production because animal-derived materials for biomedical applications are coming under increasingly stringent regulatory control for fear of contamination from conventional and nonconventional viral agents (3). Given the regulatory acceptance of $\mathrm{HA}$ produced from $\mathrm{S}$. zooepidemicus in both the US and UK, HA supplies from streptococcal fermentation are theor etically limitless, are

\footnotetext{
* To whom correspondence should be addressed.

† Murdoch University.

‡ The University of Queensland.
}

devoid of seasonal fluctuations, and vary batch to batch if a tightly controlled process is implemented (2). In addition, the potential use of recombinant DNA technology as a more accurate tool to customize the final HA product opposes the current use of downstream processing techniques $(2,3)$.

That said, literature addressing the effect of nutrient limitation and fermentation conditions on the production and quality of HA is only beginning to appear (4-7). Moreover, no model has been presented and used to analyze, optimize, and control the HA production process in fed-batch culture. As such, the development of a reliable process model describing the HA fermentation is important as it facilitates the quantification not only of the biomass production but also of product formation kinetics with a minimum, yet essential, set of parameters that relates the key pathways involved (8).

It is the purpose of this paper, therefore, to use modelbased fed-batch culture to investigate the physiological implications of glucose and complex-nitrogen-limited growth, the effect of anaerobic or aerobic conditions on both the transient and steady-state production of HA by S. zooepidemicus. This was accomplished by the use of an extended structured two-compartment model $(8,9)$ previously applied to a lactic acid-producing bacteria (10), to the two-substrate, multi-product HA fermentation under conditions of both anaerobic and aerobic growth. 


\section{Materials and Methods}

Organism, I noculum, and Media. Streptococcus equi subsp. zooepidemicus ATCC $35246 \mathrm{HA}^{+} \mathrm{Lac}^{+} \mathrm{Em}^{\mathrm{s}}$ was obtained from ATCC (Rockville MD) as freeze-dried culture and maintained in the dark at $8{ }^{\circ} \mathrm{C}$. The original vial was cultivated, and a series of stock freeze-dried cultures were prepared from this original stock. The reactor inoculum was prepared from freeze-dried culture using a series of transfers into rich media as described previously (6). For all cultures, the seed culture volume was $250 \mathrm{~L}$ unless specified otherwise. Reactor growth media for batch cultures were complex, comprised of yeast extract $\left(10 \mathrm{~g} \mathrm{~L}^{-1}\right)$, glucose $\left(20 \mathrm{~g} \mathrm{~L}^{-1}\right)$, and a mixture of inorganic salts as previously described (6). For nitrogenlimited batch culture, the growth medium was comprised of glucose $\left(\approx 21 \mathrm{~g} \mathrm{~L}^{-1}\right)$ and a mixture of inorganic salts (6). U pon depletion of the inoculum carry-over nitrogen, a mixture of yeast extract $(5.26 \mathrm{~g})$ and glucose (17.4 g) solution $(12 \mathrm{~mL}$ ) was aseptically pulse-fed.

For glucose-limited fed-batch culture, the growth medium was comprised of yeast extract $\left(10 \mathrm{~g} \mathrm{~L}^{-1}\right)$ and a mixture of inorganic salts (6). The feed glucose concentration was $133 \mathrm{~g} \mathrm{~L}^{-1}$, and the total glucose fed during the run was $40 \mathrm{~g}(\approx 0.3 \mathrm{Ls}$ of volume addition). For nitrogen-limited fed-batch culture, the growth medium was comprised of glucose $\left(40 \mathrm{~g} \mathrm{~L}^{-1}\right)$ and a mixture of inorganic salts (6). Complex-nitrogen was aseptically fed into the reactor during culture, from one of the two reservoirs of yeast extract sol utions ( 23.3 and $50.0 \mathrm{~g} \mathrm{~L}^{-1}$ ) depending on the feeding regime used.

Fermentation. All cultures were performed using a BioFlo III fermentation system (New Brunswick Scientific, Edison, NJ) under the following operating conditions, unless stated otherwise: cultivation temperature, $37^{\circ} \mathrm{C} ; \mathrm{pH}$ maintained at 6.7 by automatic sterile addition of $5 \mathrm{M} \mathrm{NaOH}$; and agitation rate was $600 \mathrm{rpm}$. Aerobic cultures were performed at an aeration rate of 0.1 I $\mathrm{min}^{-1}$. The working volume of the batch cultures was 2 I. For the fed-batch cultures, to minimize any carry over nutrient present in the inoculum, cells were separated from the inoculum medium by centrifugation and the cell pellet was resuspended in inorganic salt solution before inoculating the fermenter.

Analysis. The glucose, lactate, acetate, and HA concentrations were determined by HPLC analysis (6). Broth nitrogen concentration was measured by total $\mathrm{Kjel}$ dhal method. Capsule-free biomass and total HA concentrations were measured according to the respective procedure described by Goh (1998) (11).

Computer Simulation and Model Fitting. The HA model equations were simulated using Matlab (The MathWorks I nc. Natick, MA 01760) linked to a Fortran numerical integration routine to solve stiff systems of differential and algebraic equations (12). Typical initial conditions used for batch and fed-batch simulation are given in Table 1.

\section{Mathematical Model}

Introduction. The modeling of the HA fermentation by $\mathrm{S}$. zooepidemicus under both anaerobic and aerobic conditions adopts the model framework previously employed by Williams (1967), Esener et al. (1981), and Niel sen et al. (1991a, b): a structured two-compartment model $(8-10,13)$. According to the two-compartment model description, one compartment is defined as the "active" part (A-compartment) and the other as the "inactive" part (G-compartment). As the name implies, the former compartment comprises the synthesizing
Table 1. Typical Initial Conditions for Batch and Fed-Batch Growth

\begin{tabular}{|c|c|c|c|}
\hline state variable & batch & fed-batch & units \\
\hline$x_{\text {to }}$ & 0.18 & 0.15 & gdw $L^{-1}$ \\
\hline $\mathrm{S}_{0}$ & 19.9 & 0.01 & $\mathrm{~g}_{\mathrm{GL}} \mathrm{L}^{-1}$ \\
\hline $\mathrm{S}_{\mathrm{fo}}$ & na & 133.0 & $\mathrm{~g}_{\mathrm{GL}} \mathrm{L}^{-1}$ \\
\hline $\mathrm{S}_{\mathrm{No}}$ & 1.35 & 1.35 & $9_{T N} L^{-1}$ \\
\hline $\mathrm{S}_{\mathrm{Nf}}$ & na & 0.0 & \\
\hline $\mathrm{LA}_{\circ}$ & 0.39 & 0.24 & $\mathrm{~g}_{\mathrm{LA}} \mathrm{L}^{-1}$ \\
\hline $\mathrm{HA}_{\mathrm{O}}$ & 0.03 & 0.01 & $\mathrm{~g}_{\mathrm{HA}} \mathrm{L}^{-1}$ \\
\hline $\mathrm{V}_{0}$ & na & 1.7 & $\mathrm{~L}$ \\
\hline $\mathrm{X}_{\mathrm{AO}}$ & 0.33 & same & gxa $g_{d w^{-1}}$ \\
\hline$X_{G o}$ & 0.66 & same & $g_{x g} g_{d w}^{-1}$ \\
\hline$\mu_{\mathrm{o}}$ & 0.52 & same & $\mathrm{h}^{-1}$ \\
\hline$r_{10}$ & 3.10 & same & $g_{G L} g_{d w^{-1}} h^{-1}$ \\
\hline$r_{20}$ & 0.06 & same & GTN $\mathrm{gdw}^{-1} \mathrm{~h}^{-1}$ \\
\hline$r_{30}$ & 0.30 & same & $\mathrm{g}_{\mathrm{xa}} \mathrm{gdw}^{-1} \mathrm{~h}^{-1}$ \\
\hline$r_{40}$ & 0.01 & same & 9TN $g d^{-1} h^{-1}$ \\
\hline
\end{tabular}

components of the cell (ribosomes, mRNA, tRNA, various enzymes, etc.), in which the main constituent is the protein-synthesizing system, made up of about $60 \%$ RNA. The relative size of A-compartment is defined by the measured RNA content, assumed constant at all operating conditions unless the metabolic pathways are radically altered. The G-compartment comprises the genetic and structural materials such as DNA, lipids, lipopolysaccharides, proteins, and carbohydrates. The G-compartment is produced at a rate depending on the size of A-compartment, but the rate of formation of $A$ is independent of G. Therefore, the A-compartment plays the central role in determining the rate of growth; that is, all the reaction rates are directly linked to the size of this pool.

Constraints. There are four principle constraints important to the HA model. First, the model is only valid for conditions of $\mathrm{pH}$ and temperature that optimize $\mathrm{HA}$ production: $\mathrm{pH} 6.7( \pm 0.2), 37{ }^{\circ} \mathrm{C}(6)$. Second, as mass transfer efficiency and uniform $\mathrm{pH}$ control are affected by HA concentration-the apparent viscosity of the medium is correlated to the broth HA concentrationthe broth HA concentration should remain below $3.0 \mathrm{~g}$ $\mathrm{L}^{-1}$ in order to minimize mass transfer problems (14). Third, although mathematically appropriate, the model should not be applied to continuous culture. The problem is one of strain instability, which leads to the development of a dominant acapsular (non-HA-producing strain with higher specific growth rate) mutant in continuous culture $(7,14)$ Finally, the model is not suitable for glucose concentrations exceeding $50 \mathrm{~g} \mathrm{~L}^{-1}$. The problem is that lactic acid bacteria such as S. zooepidemicus produces large quantities of lactate from the catabol ism of glucose ( 75 to $85 \%$ conversion), and results have shown that both growth and HA production are inhibited for broth lactate concentrations above $39 \mathrm{~g} \mathrm{~L}^{-1}(11,14)$.

Anaerobic Growth. Model Formulation. The stoichiometry and mass balances describing the anaerobic fermentation of S. zooepi demicus are presented in Tables 2 and 3, respectively, while the model parameters are presented in Table 4. Whereas stoichiometric coefficients determined for Streptococcus cremoris (13) were expressed on the basis of nitrogen as protein, in this work they have been expressed on a total nitrogen basis, which removes the need to assume a general protein nitrogen content, since total nitrogen in the medium can be measured directly.

Parameter Estimation. The estimate of the stoichiometric coefficient, $\gamma_{21}\left(6.7 \mathrm{gX}_{\mathrm{A}} \mathrm{g}_{\mathrm{TN}^{-1}}\right)$, was cal culated from the respective nitrogen content of RNA and protein, since $X_{A}$ is assumed to be $60 \%$ RNA and $40 \%$ protein (13). The 
Table 2. HA Stoichiometry for Anaerobic Growth

$$
\begin{array}{ll}
\mathrm{S} \stackrel{\mathrm{r}_{1}}{\rightarrow} \beta_{11} \mathrm{LA} & \text { eq } \\
\mathrm{S}_{\mathrm{N}}+\alpha_{21} \mathrm{~S} \stackrel{\mathrm{r}_{2}}{\rightarrow} \gamma_{21} \mathrm{X}_{\mathrm{A}} & \text { eq } \\
\mathrm{X}_{\mathrm{A}} \stackrel{\mathrm{r}_{3}}{\rightarrow} \gamma_{32} \mathrm{X}_{\mathrm{G}} & \text { eq } \\
\mathrm{S}_{\mathrm{N}}+\alpha_{42} \mathrm{~S} \stackrel{\mathrm{r}_{4}}{\rightarrow} \beta_{42} \mathrm{HA} & \text { eq }
\end{array}
$$

Table 3. HA Model Equations for Anaerobic Growth

$$
\begin{aligned}
& \frac{\mathrm{d} \mathrm{X}_{\mathrm{T}}}{\mathrm{dt}}=\mu \mathrm{X}_{\mathrm{T}}-\frac{\mathrm{F}}{\mathrm{V}} \mathrm{X}_{\mathrm{T}} \\
& \frac{\mathrm{dS}}{\mathrm{dt}}=-\left(\mathrm{r}_{1}+\alpha_{21} \mathrm{r}_{2}+\alpha_{42} \mathrm{r}_{4}\right) \mathrm{X}_{\mathrm{T}}+\frac{\mathrm{F}}{\mathrm{V}}\left(\mathrm{S}_{\mathrm{f}}-\mathrm{S}\right) \\
& \frac{\mathrm{dS}_{\mathrm{N}}}{\mathrm{dt}}=-\left(\mathrm{r}_{2}+\mathrm{r}_{4}\right) \mathrm{X}_{\mathrm{T}}+\frac{\mathrm{F}}{\mathrm{V}}\left(\mathrm{S}_{\mathrm{Nf}}-\mathrm{S}_{\mathrm{N}}\right) \\
& \frac{\mathrm{dLA}}{\mathrm{dt}}=\beta_{11} \mathrm{r}_{1} \mathrm{X}_{\mathrm{T}}-\frac{\mathrm{F}}{\mathrm{V}} \mathrm{LA} \\
& \frac{\mathrm{dHA}}{\mathrm{dt}}=\beta_{42} \mathrm{r}_{4} \mathrm{X}_{\mathrm{T}}-\frac{\mathrm{F}}{\mathrm{V}} \mathrm{HA} \\
& \frac{d X_{A}}{d t}=\gamma_{21} r_{2}-r_{3}-\mu X_{A} \\
& \frac{\mathrm{d} \mathrm{X}_{\mathrm{G}}}{\mathrm{dt}}=\gamma_{32} r_{3}-\mu \mathrm{X}_{\mathrm{G}} \\
& \frac{\mathrm{dV}}{\mathrm{dt}}=\mathrm{F} \\
& \mu=\gamma_{21} r_{2}-\left(1-\gamma_{32}\right) r_{3} \\
& \mathrm{r}_{1}=\mathrm{k}_{1} \frac{\mathrm{S}}{\mathrm{S}+\mathrm{K}_{\mathrm{S} 1}} \mathrm{X}_{\mathrm{A}} \\
& r_{2}=k_{2} \frac{S}{S+K_{S 2}} \frac{S_{N}}{S_{N}+K_{S N 2}} X_{A} \\
& r_{3}=k_{3} \frac{S}{S+K_{S 3}} \frac{S_{N}}{S_{N}+K_{S N 3}} X_{A} \\
& r_{4}=k_{4} \frac{S}{S+K_{S 4}} \frac{S_{N}}{S_{N}+K_{S N 4}} x_{A}
\end{aligned}
$$

value of $\gamma_{32}$, which specifies the yield coefficient for macromolecule synthesis from precursor building blocks, was taken to be near $100 \%$ (13). The stoichiometric coefficient $\alpha_{21}\left(2.2 \mathrm{~g}_{\mathrm{TN}} \mathrm{g}_{\mathrm{GL}}{ }^{-1}\right)$ was calculated using the same 60-40 ratio and assuming that the only carbon derived from glucose is present (as pentose) in the base units of the RNA. All other carbon consumed in the production of $\mathrm{X}_{\mathrm{A}}-$ whether present in the nucleotide bases

\begin{tabular}{|c|c|c|c|c|}
\hline & S. cremoris & estimated & fit & units \\
\hline \multicolumn{5}{|c|}{ Rate Constants } \\
\hline $\mathrm{k}_{1}$ & 5.23 & 5.23 & 11.0 & $g_{G L} g_{X a}{ }^{-1} h^{-1}$ \\
\hline $\mathrm{k}_{2}$ & 0.24 & 0.24 & 0.21 & $\mathrm{gN}_{\mathrm{N}} \mathrm{gxa}^{-1} \mathrm{~h}^{-1}$ \\
\hline $\mathrm{k}_{3}$ & 1.23 & 1.23 & 1.15 & gxa gxa $\mathrm{h}^{-1}$ \\
\hline $\mathrm{k}_{4}$ & & 0.027 & 0.046 & $\mathrm{gN}_{\mathrm{N}} \mathrm{gxa}^{-1}$ \\
\hline \multicolumn{5}{|c|}{ Saturation Constants } \\
\hline $\mathrm{Ks}_{1}$ & 0.010 & 0.010 & 0.010 & $g_{G L} L^{-1}$ \\
\hline $\mathrm{Ks}_{2}$ & 0.032 & 0.032 & 0.032 & $\mathrm{~g}_{\mathrm{GL}} \mathrm{L}^{-1}$ \\
\hline $\mathrm{Ks}_{3}$ & 0.026 & 0.026 & 0.026 & $\mathrm{~g}_{\mathrm{GL}} \mathrm{L}^{-1}$ \\
\hline $\mathrm{KS}_{4}$ & & 0.010 & 0.010 & $\mathrm{~g}_{\mathrm{GL}} \mathrm{L}^{-1}$ \\
\hline $\mathrm{Ksn}_{2}$ & 0.210 & 0.210 & 0.210 & $g_{N} L^{-1}$ \\
\hline $\mathrm{Ksn}_{3}$ & 0.210 & 0.210 & 0.210 & $g_{N} L^{-1}$ \\
\hline $\mathrm{Ksn}_{4}$ & 0.210 & 0.210 & 0.210 & $g_{N} L^{-1}$ \\
\hline \multicolumn{5}{|c|}{ Stoichiometric Coefficients } \\
\hline$\alpha_{21}$ & 1.0 & 2.2 & 2.2 & $g_{G L} g_{N}^{-1}$ \\
\hline$\beta_{11}$ & 1.0 & 0.99 & 0.99 & $\mathrm{~g}_{\mathrm{LA}} \mathrm{g}_{\mathrm{G}} \mathrm{L}^{-1}$ \\
\hline$\beta_{42}$ & & 27.6 & 27.6 & $\mathrm{~g}_{\mathrm{HA}} \mathrm{gN}^{-1}$ \\
\hline$\gamma_{21}$ & 7.86 & 6.7 & 8.8 & $9 \times a 9_{N}^{-1}$ \\
\hline$\gamma_{32}$ & 0.97 & 0.98 & 0.98 & $9 \times g=9 a^{-1}$ \\
\hline$\alpha_{42}$ & & 25.7 & 25.7 & $\mathrm{~g}_{\mathrm{GL}} \mathrm{gN}^{-1}$ \\
\hline
\end{tabular}
of the RNA or in the protein-was assumed to be derived from the yeast extract. Our estimate for $\alpha_{42}\left(25.7 \mathrm{~g}_{\mathrm{GL}}\right.$ $\left.9_{\mathrm{TN}}{ }^{-1}\right)$, which represents the mass fraction of glucose on a nitrogen basis consumed in the production of $\mathrm{HA}$, was made assuming a molar glucose-to-glutamine ratio of 2 per mole of HA formed.

A preliminary estimate $\left(0.99 \mathrm{~g}_{\mathrm{LA}} \mathrm{g}_{\mathrm{GL}}{ }^{-1}\right)$ for $\beta_{11}$ was estimated assuming a near $100 \%$ mass efficiency in the production of Iactic acid, since no other byproducts have been detected in concentrations greater than $0.5 \mathrm{~g} \mathrm{~L}^{-1}$ in anaerobic batch growth of S. zooepidemicus $(7,11)$. The coefficient $\beta_{42}$, which represents the mass fraction of HA produced per gram of nitrogen, was estimated (27.6 $\mathrm{g}_{\mathrm{HA}} \mathrm{g}_{\mathrm{TN}}{ }^{-1}$ ) from the molecular formula of the repeating unit of $\mathrm{HA}$.
Table 4. HA Model Parameters for Anaerobic Growth

The theoretically estimated model parameters were then adjusted as necessary by comparison against experimental batch data (see Table 4). Model fitting was assisted by the results of differential parameter sensitivity analysis performed on the HA model (15). The values of the rate constants $\mathrm{k}_{1}, \mathrm{k}_{2}, \mathrm{k}_{3}$, and $\mathrm{k}_{4}$ required significant adjustment, whereas, in general, the stoichiometric coefficients remained unchanged-our theoretical estimates agreed well with experimental data and that determined for S. cremoris (13). This is not surprising in view of the fact that the two bacteria share similar pathways for glucose and nitrogen assimilation.

The principle deviation was found in $\alpha_{21}$, which represents the mass fraction of glucose consumed on a nitrogen basis in the pathway producing $X_{A}$ (see eq 2 in Table 2). The value for our S. zooepidemi cus was found to be greater, by a factor of 2, than that determined for S. cremoris. This discrepancy is due to the assumption made regarding the percentage of $X_{A}$ carbon derived from glucose. As the fraction of biomass carbon derived from peptide carbon increases, $\alpha_{21}$ approaches a value of unity, as observed for some strains of lactic acid bacteria (3, 13). As can be seen in Table 4, however, our estimated value of $\alpha_{21}$ correlated well with the experimental data.

Aerobic Growth. Model Formulation. Aerobic growth of $\mathrm{S}$. zooepidemicus was modeled using the anaerobic model as a base while concomitantly incorporating the additional stoichiometry and mass balances necessary to account for the more diverse metabolism: the presence of hydrogen peroxide and acetate, decreased biomass production, and finally, increased HA production. As such, the aerobic model encompasses a considerably greater number of equations and parameters than its anaerobic counterpart; the stoichiometry and mass balances are presented in Tables 5 and 6 and their foundation will now be addressed.

Stoichiometry for Oxygen Metabolism. To develop the reaction stoichiometry particular to aerobic growth of S. zooepidemicus, we noted that other streptococci can utilize oxygen when grown under aerated conditions; however, it is not capable of oxidative-respiratory metabolism since key enzymes of the TCA cycle and electron transport chain are absent in the cell. Although information on the oxygen metabolism of S. zooepidemicus has not been published, reactions involving molecular oxygen or oxygen metabolites by the other Streptococcus species 
Table 5. HA Stoichiometry for Aerobic Growtha

$$
\begin{array}{ll}
\mathrm{s} \stackrel{\mathrm{r}_{1}}{\rightarrow} \beta^{\prime}{ }_{11} \mathrm{la} & \text { eq } 18 \\
\mathrm{~s}+\alpha^{\prime}{ }_{21} \mathrm{~S}_{\mathrm{O}} \stackrel{\mathrm{r}_{2}}{\rightarrow} \beta^{\prime}{ }_{21} \mathrm{ace}+\beta_{22}^{\prime} \mathrm{CO}_{2}+\beta_{23}^{\prime} \mathrm{H}_{2} \mathrm{O}_{2} & \text { eq } 19 \\
\mathrm{~S}_{\mathrm{N}}+\alpha^{\prime}{ }_{31} \mathrm{~S} \stackrel{\mathrm{r}_{3}}{\rightarrow} \gamma^{\prime}{ }_{31} \mathrm{X}_{\mathrm{A}} & \text { eq } 20 \\
\mathrm{X}_{\mathrm{A}} \stackrel{\mathrm{r}_{4}}{\rightarrow} \gamma^{\prime}{ }_{42} \mathrm{X}_{\mathrm{G}} & \text { eq } 21 \\
\mathrm{~S}_{\mathrm{N}}+\alpha^{\prime}{ }_{51} \mathrm{~S} \stackrel{\mathrm{r}_{5}}{\rightarrow} \beta_{51}^{\prime} \mathrm{ha} & \text { eq } 22 \\
\mathrm{X}_{\mathrm{A}}+\alpha^{\prime}{ }_{61} \mathrm{H}_{2} \mathrm{O}_{2} \stackrel{\mu}{\rightarrow} \gamma^{\prime}{ }_{42} \mathrm{X}_{\mathrm{G}} & \text { eq } 23
\end{array}
$$

a Primes are used to differentiate the aerobic from the anaerobic model.

are well documented; the reactions are summarized in Table 7 (16).

The aerobic model, then, assumes that oxygen consumption by S. zooepidemicus is predominantly due to the combined activity of NADH oxidases described by eqs 42 and 43 (see Table 7). Admittedly, support for this assumption, derived from the detection of hydrogen peroxide in aerobic cultures of S. zooepidemicus, is open to comment as its broth concentration was too low to be quantified accurately (11). That said, there are some important points strengthening this assumption. First, although the enzymatic source of hydrogen peroxide in S. zooepidemicus has yet to be identified, Zitzel sberger et al. (1984) studied the occurrence of NADH oxidases and peroxidase in various streptococci and found that the NADH oxidases were far more widespread-present in all 23 species tested - than the peroxidases (17). Furthermore, only one of the 23 species exami ned possessed the enzyme pyruvate oxidase (17). Finally, hydrogen peroxide production has been attributed to the activity of $\mathrm{H}_{2} \mathrm{O}_{2-}$ forming $\mathrm{NADH}$ oxidase al one, even though dismutation of superoxide also generates $\mathrm{H}_{2} \mathrm{O}_{2}$; its contribution has been shown to be less than substantial (16).

For this reason, a weighted combination of eqs 42 and 43 was accepted; their relative weighting (0.21) was assumed to be the equivalent to that found for $\mathrm{S}$. mutans (18). Hence, the combined molar stoichiometry of the $\mathrm{H}_{2} \mathrm{O}_{2}$-forming and $\mathrm{H}_{2} \mathrm{O}$-forming $\mathrm{NADH}$ oxidase reactions (eqs 42 and 43 in Table 7) was consolidated as follows:

$$
\begin{aligned}
\mathrm{NADH}+\mathrm{H}^{+}+ & 0.79 \mathrm{O}_{2} \rightarrow \\
& \quad 0.58 \mathrm{H}_{2} \mathrm{O}_{2}+0.41 \mathrm{H}_{2} \mathrm{O}+2 \mathrm{NAD}^{+}
\end{aligned}
$$

The consumption of NADH is now linked to the production of carbon dioxide and acetate-two phenomena, observed under conditions of aerobic growth, which will now be discussed.

Heterolactic Glucose Catabolism. As in the case of other lactic acid bacteria, oxygen metabolism can provide S. zooepidemicus an additional route for $\mathrm{NAD}^{+}$regeneration, required for the continual operation of glycolysis (16). This would reduce the need to reoxidize NADH via the putative lactate dehydrogenase pathway, which was reflected by the lower lactic acid yield observed under aerated conditions relative to that of equivalent anaerobic cultures (11). As a result, a substantial amount of pyruvate is diverted to form acetate, with the concomitant production of carbon dioxide as well as ATP. The pyruvate-formate lyase enzyme is completely inhibited by oxygen under aerated conditions $(19,20)$; hence formate was not formed in the medium (11). Considering
Table 6. HA Model Equations for Aerobic Growtha

$$
\begin{aligned}
& \frac{\mathrm{dS}}{\mathrm{dt}}=-\left(\mathrm{r}_{1}^{\prime}+\mathrm{r}_{2}^{\prime}+\alpha^{\prime}{ }_{31} \mathrm{r}_{3}{ }_{3}+\alpha^{\prime}{ }_{51} \mathrm{r}_{5}\right) \mathrm{X}_{\mathrm{T}}+\frac{\mathrm{F}}{\mathrm{V}}\left(\mathrm{S}_{\mathrm{f}}-\mathrm{S}\right) \quad \text { eq } 24 \\
& \frac{d S_{N}}{d t}=-\left(r^{\prime}{ }_{3}+r_{5}^{\prime}\right) X_{T}+\frac{F}{V}\left(S_{N f}-S_{N}\right) \\
& \frac{d S_{O}}{d t}=-\alpha_{21}^{\prime} r_{2}^{\prime} X_{T}+K_{L} a\left(S_{O f}-S_{O}\right) \\
& \frac{\mathrm{dLA}}{\mathrm{dt}}=\beta^{\prime}{ }_{11} \mathrm{r}_{1}{ }_{1} \mathrm{X}_{\mathrm{T}}-\frac{\mathrm{F}}{\mathrm{V}} \mathrm{LA} \\
& \frac{\mathrm{dACE}}{\mathrm{dt}}=\beta^{\prime}{ }_{21} \mathrm{r}_{2}{ }_{2} \mathrm{X}_{\mathrm{T}}-\frac{\mathrm{F}}{\mathrm{V}} \mathrm{ACE} \\
& \frac{\mathrm{dCO}}{\mathrm{dt}}=\beta_{22}^{\prime} \mathrm{r}_{2}^{\prime} \mathrm{X}_{\mathrm{T}}-\frac{\mathrm{F}}{\mathrm{V}} \mathrm{CO}_{2} \\
& \frac{\mathrm{dHA}}{\mathrm{dt}}=\beta^{\prime}{ }_{51} \mathrm{r}_{5}{ }_{5} \mathrm{X}_{\mathrm{T}}-\frac{\mathrm{F}}{\mathrm{V}} \mathrm{HA} \\
& \frac{\mathrm{dH}_{2} \mathrm{O}_{2}}{\mathrm{dt}}=\beta^{\prime}{ }_{23} \mathrm{r}^{\prime}{ }_{2} \mathrm{X}_{\mathrm{T}}-\alpha^{\prime}{ }_{61} \mu^{\prime} \mathrm{X}_{\mathrm{A}} \mathrm{X}_{\mathrm{T}}-\frac{\mathrm{F}_{\mathrm{V}}}{\mathrm{H}_{2} \mathrm{O}_{2}} \\
& \frac{\mathrm{d} \mathrm{X}_{\mathrm{T}}}{\mathrm{dt}}=\left(\mu^{\prime}-\frac{\mathrm{F}}{\mathrm{V}}\right) \mathrm{X}_{\mathrm{T}} \\
& \frac{\mathrm{d} \mathrm{X}_{\mathrm{A}}}{\mathrm{dt}}=\gamma^{\prime}{ }_{31} \mathrm{r}_{3}^{\prime}-\mathrm{r}_{4}^{\prime}-\mu^{\prime} \mathrm{X}_{\mathrm{A}}-\frac{\mu^{\prime} \mathrm{H}_{2} \mathrm{O}_{2}}{\alpha^{\prime}{ }_{61} \mathrm{X}_{\mathrm{T}}} \mathrm{CO}_{2} \\
& \frac{\mathrm{d} \mathrm{X}_{\mathrm{G}}}{\mathrm{dt}}=\gamma^{\prime}{ }_{42} \mathrm{r}_{4}^{\prime}-\mu^{\prime} \mathrm{X}_{\mathrm{G}}+\frac{\mu \gamma^{\prime}{ }_{42} \mathrm{H}_{2} \mathrm{O}_{2}}{\alpha_{61}^{\prime} \mathrm{X}_{\mathrm{T}}} \\
& \mu^{\prime}=\gamma_{31}^{\prime} r_{3}^{\prime}-\left(1-\gamma_{42}^{\prime}\right) r_{4}^{\prime} \\
& \mathrm{K}_{\mathrm{L}} \mathrm{a}=16.9-0.3375 \mathrm{t} \\
& \mathrm{r}_{1}^{\prime}=\mathrm{k}_{1}^{\prime}\left(\frac{\mathrm{S}}{\mathrm{S}+\mathrm{K}_{\mathrm{S} 1}^{\prime}}\right) \mathrm{x}_{\mathrm{A}} \\
& r_{2}^{\prime}=k_{2}^{\prime}\left(\frac{S}{S+K_{S 2}^{\prime}}\right)\left(\frac{S_{O}}{S_{O}+K_{S O 2}^{\prime}}\right) x_{A} \\
& \mathrm{r}_{3}^{\prime}=\mathrm{k}_{3}^{\prime}\left(1-\frac{\mathrm{H}_{2} \mathrm{O}_{2}}{\mathrm{H}_{2} \mathrm{O}_{2}{ }^{*}}\right)^{\mathrm{n}}\left(\frac{\mathrm{S}}{\mathrm{S}+\mathrm{K}_{\mathrm{S3}}^{\prime}}\right)\left(\frac{\mathrm{S}_{\mathrm{N}}}{\mathrm{S}_{\mathrm{N}}+\mathrm{K}_{\mathrm{SN} 3}^{\prime}}\right) \mathrm{X}_{\mathrm{A}} \\
& \mathrm{r}_{3}^{\prime}=\mathrm{k}_{3}^{\prime}\left(1-\frac{\mathrm{H}_{2} \mathrm{O}_{2}}{\mathrm{H}_{2} \mathrm{O}_{2}{ }^{*}}\right)^{\mathrm{n}}\left(\frac{\mathrm{S}}{\mathrm{S}+\mathrm{K}_{\mathrm{S3}}^{\prime}}\right)\left(\frac{\mathrm{S}_{\mathrm{N}}}{\mathrm{S}_{\mathrm{N}}+\mathrm{K}_{\mathrm{SN} 3}^{\prime}}\right) \mathrm{x}_{\mathrm{A}} \\
& r_{5}^{\prime}=k_{5}^{\prime}\left(\frac{S}{S+K^{\prime}{ }_{S 5}}\right)\left(\frac{S_{N}}{S_{N}+K_{S N 5}^{\prime}}\right) x_{A}
\end{aligned}
$$

a Primes are used to differentiate the aerobic from the anaerobic model.

the importance of maintaining redox balance within the cell and the significant onset of acetate formation in the presence of oxygen, acetate production is expected to be cl osely linked to oxygen metabolism via the nicotinamide adenine dinucleotide metabolite. Therefore, the two metabolic processes were combined into one reaction and represented as follows:

$$
\begin{aligned}
& 0.5 \text { glucose }+2\left(\mathrm{NADH}+\mathrm{H}^{+}\right)+1.58 \mathrm{O}_{2} \rightarrow \\
& \text { acetate }+\mathrm{CO}_{2}+1.16 \mathrm{H}_{2} \mathrm{O}_{2}+0.42 \mathrm{H}_{2} \mathrm{O}+2 \mathrm{NAD}^{+}
\end{aligned}
$$

This balance was used as the basis for developing eq 19 and for estimating the aerobic model parameters $\alpha_{1}^{\prime}, \beta_{21}^{\prime}$, $\beta_{22}^{\prime}$, and $\beta_{23}^{\prime}$, which are unique to the aerobic model. In the final model framework, the model stoichiometry (eq 19) omits the NADH/NAD ${ }^{+}$metabolites and water, since a complete account of these components was not achievable at this stage. 
Table 7. Reactions Involving Molecular Oxygen or Oxygen Metabolites Mediated by Enzymes of Streptococci (Condon, 1987 No. 43)

\begin{tabular}{lll}
\hline \multicolumn{1}{c}{ enzyme } & \multicolumn{1}{c}{ reaction } \\
\hline $\mathrm{NADH}-\left(\mathrm{H}_{2} \mathrm{O}_{2}\right)$ oxidase & $\mathrm{NADH}+\mathrm{H}^{+}+\mathrm{O}_{2} \rightarrow \mathrm{NAD}^{+}+\mathrm{H}_{2} \mathrm{O}_{2}$ & eq 42 \\
$\mathrm{NADH}-\left(\mathrm{H}_{2} \mathrm{O}\right)$ oxidase & $2 \mathrm{NADH}+2 \mathrm{H}^{+}+\mathrm{O}_{2} \rightarrow 2 \mathrm{NAD}^{+}+2 \mathrm{H}_{2} \mathrm{O}$ & eq 43 \\
$\mathrm{NADH}$ peroxidase & $\mathrm{NADH}+\mathrm{H}^{+}+\mathrm{H}_{2} \mathrm{O}_{2} \rightarrow \mathrm{NAD}^{+}+2 \mathrm{H}_{2} \mathrm{O}$ & eq 44 \\
pyruvate oxidase & pyruvate + phosphate $+\mathrm{O}_{2} \rightarrow$ acetyl phosphate $+\mathrm{CO}_{2}+\mathrm{H}_{2} \mathrm{O}_{2}$ & eq 45
\end{tabular}

a Equations 42 and 43 were used, in part, to devel op the unique reaction stoichiometry for aerobic growth of S. zooepidemicus.

Growth Inhi bition. Table 8 presents a range of yields for aerobic and anaerobic batch growth of S. zooepidemicus under various growth conditions. The lower cell yield ( $g d w \mathrm{~g}_{\mathrm{GL}}{ }^{-1}$ ) obtained for aerated growth was assumed to be due to the toxicity of $\mathrm{H}_{2} \mathrm{O}_{2}$, since our microorganism is catalase-negative $(21,22)$. Similar growth inhibition has been demonstrated in various lactic acid bacteria, including a number of Streptococcus species (23-28). As little is known concerning the mechanism of $\mathrm{H}_{2} \mathrm{O}_{2}$ inhibition on streptococcal growth, the phenomenon has been incorporated into our aerobic model by a nonlinear form of inhibition applied to the kinetic rate constant $k^{\prime}{ }_{3}$ which governs $X_{A}$ formation (eq 39) (29). The " $n$ " parameter denotes the toxicity index of $\mathrm{H}_{2} \mathrm{O}_{2}$, and it reflects the extent of the inhibition on growth.

The inhibition terms permits the kinetic rate constant $\left(\mathrm{K}_{3}^{\prime}\right)$ to be reduced by the internal $\mathrm{H}_{2} \mathrm{O}_{2}$ concentration in a concentration-dependent manner that is weighted by the critical $\mathrm{H}_{2} \mathrm{O}_{2}$ concentration $\left(\mathrm{H}_{2} \mathrm{O}_{2} *\right)$. As such, when the cellular $\mathrm{H}_{2} \mathrm{O}_{2}$ level reaches the critical value, the reaction $\left(r^{\prime}{ }_{3}\right)$ becomes zero and $X_{A}$ formation totally shuts down. During the inhibition process, $\mathrm{H}_{2} \mathrm{O}_{2}$ may bind reversibly or irreversibly with components of $\mathrm{X}_{\mathrm{A}}$ compartment. As such, in our model any permanent inactivation of $X_{A}$ is taken to be equivalent to the formation of $X_{G}$ (eqs 23 and 34).

Oxygen Transfer Rate. The $\mathrm{K}_{\mathrm{L}} \mathrm{a}\left(\mathrm{h}^{-1}\right)$ of the model was described by a linear relationship as a function of fermentation time. This was an empirical relationship constructed from a 2-point data as determined by the dynamic gassing-out method using sterile nitrogen (data not shown). Thefirst data point was obtained at the start of an aerated batch culture (at $0.1 \mathrm{~L} / \mathrm{min}$ ), while the other was measured at the end of the run, usually $8 \mathrm{~h}$.

Parameter Estimation. The initial estimates for the aerobic model parameters are presented in Table 8 al ong with their anaerobic counterparts for comparison. Initially, values for analogous stoichiometric coefficients and saturation constants were taken from the anaerobic model, as their major metabolic processes are fundamentally identical. Thereafter, estimates for $\alpha_{21}^{\prime}, \beta_{21}^{\prime}, \beta_{22}^{\prime}$, and $\beta_{23}^{\prime}$ were estimated from the stoichiometry previously devel oped for heterolactic gl ucose catabol ism. In addition, the parameter $\alpha^{\prime}{ }_{61}$, which represents the grams of hydrogen peroxide produced per gram of $X_{A}$, was arbitrarily assigned as 0.001 and later adjusted as necessary. The saturation constant $K_{\text {S2 }}^{\prime}$ was assigned the same value as $K^{\prime}{ }_{s 1}$ since a part of the reaction governed by $r_{2}^{\prime}$ also constitutes glucose catabol ism. The saturation constant for oxygen uptake, $\mathrm{K}^{\prime}$ so2, was based on oxygen substrate data of bacterial fermentation (30).

With regards to rate constants novel to aerobic growth, lactic acid productivity has been observed to be reduced by as much as $18 \%$ under aerated conditions (11); thus the kinetic rate constant for lactic acid production $\left(\mathrm{k}_{1}^{\prime}\right)$ was taken to be $82 \%$ of its anaerobic counterpart. Furthermore, $\mathrm{k}_{2}^{\prime}$ was estimated to be approximately $13 \%$ the value assigned to $\mathrm{K}^{\prime}{ }_{1}$ since this percentage carbon was diverted to produce acetate and carbon dioxide at the expense of lactate. The carbon content of acetic acid and
Table 8. HA Model Parameters for Aerobic Growtha

\begin{tabular}{|c|c|c|c|c|}
\hline & anaerobic & estimated & fitted & units \\
\hline \multicolumn{5}{|c|}{ Rate Constants } \\
\hline $\mathrm{k}_{1}^{\prime}$ & $11.0\left(\mathrm{k}_{1}\right)$ & 9.0 & 9.7 & $\mathrm{gGL}_{\mathrm{G}} \mathrm{gxa}^{-1} \mathrm{~h}^{-1}$ \\
\hline $\mathrm{k}_{2}^{\prime}$ & & 1.2 & 1.9 & $g_{G L} g_{x a}^{-1} h^{-1}$ \\
\hline $\mathrm{k}_{3}^{\prime}$ & $0.21\left(\mathrm{k}_{2}\right)$ & 0.21 & 0.21 & $\mathrm{~g}_{\mathrm{N}} \mathrm{gxa}^{-1} \mathrm{~h}^{-1}$ \\
\hline $\mathrm{k}_{4}^{\prime}$ & $1.15\left(\mathrm{k}_{3}\right)$ & 1.15 & 1.15 & $9 \times a 9 \times a^{-1} h^{-1}$ \\
\hline $\mathrm{k}_{5}^{\prime}$ & $0.046\left(k_{4}\right)$ & 0.055 & 0.052 & $\mathrm{gN}_{\mathrm{N}} \cdot \mathrm{gxa}^{-1} \mathrm{~h}^{-1}$ \\
\hline \multicolumn{5}{|c|}{ Saturation Constants } \\
\hline$K_{S 1}^{\prime}$ & $0.01\left(K_{\mathrm{S} 1}\right)$ & 0.01 & 0.01 & $\mathrm{~g}_{\mathrm{GL}} \mathrm{L}^{-1}$ \\
\hline $\mathrm{K}_{\mathrm{S} 2}^{\prime}$ & & 0.01 & 0.01 & $\mathrm{~g}_{\mathrm{GL}} \mathrm{L}^{-1}$ \\
\hline $\mathrm{K}_{\mathrm{S3}}^{\prime}$ & $0.032\left(K_{\mathrm{s} 2}\right)$ & 0.032 & 0.032 & $\mathrm{~g}_{\mathrm{GL}} \mathrm{L}^{-1}$ \\
\hline$K^{\prime}{ }_{S 4}$ & $0.026\left(\mathrm{~K}_{\mathrm{s} 3}\right)$ & 0.026 & 0.026 & $\mathrm{~g}_{\mathrm{GL}} \mathrm{L}^{-1}$ \\
\hline$K^{\prime}{ }_{55}$ & $0.01\left(K_{\mathrm{S} 4}\right)$ & 0.01 & 0.01 & $\mathrm{~g}_{\mathrm{GL}} \mathrm{L}^{-1}$ \\
\hline $\mathrm{K}_{\mathrm{SO} 2}^{\prime}$ & & 0.00032 & 0.00032 & go2 $L^{-1}$ \\
\hline $\mathrm{K}_{\mathrm{SN} 3}^{\prime}$ & $0.21\left(\mathrm{~K}_{\mathrm{SN} 2}\right)$ & 0.21 & 0.21 & $g_{N} L^{-1}$ \\
\hline $\mathrm{K}_{\text {SN4 }}^{\prime}$ & $0.21\left(\mathrm{~K}_{\mathrm{SN} 3}\right)$ & 0.21 & 0.21 & $g_{N} L^{-1}$ \\
\hline $\mathrm{K}^{\prime}$ SN5 & $0.21\left(\mathrm{~K}_{\mathrm{SN} 4}\right)$ & 0.21 & 0.21 & $g_{N} L^{-1}$ \\
\hline \multicolumn{5}{|c|}{ Stoichiometric Coefficients } \\
\hline$\alpha_{21}^{\prime}$ & & 0.56 & 0.56 & $\mathrm{go}_{2} \mathrm{gGL}^{-1}$ \\
\hline$\alpha^{\prime} 31$ & $2.2\left(\alpha_{21}\right)$ & 2.2 & 3.92 & $g_{G L} g_{N}^{-1}$ \\
\hline$\alpha^{\prime}{ }_{51}$ & $25.7\left(\alpha_{42}\right)$ & 25.71 & 25.71 & $\mathrm{~g}_{\mathrm{GL}} \mathrm{gN}^{-1}$ \\
\hline$\alpha_{61}^{\prime}$ & & 0.001 & 1.47 & $\mathrm{~g}_{\mathrm{H} 2 \mathrm{O} 2} \mathrm{gxa}^{-1}$ \\
\hline$\beta_{11}^{\prime}$ & $0.99\left(\beta_{11}\right)$ & 0.99 & 0.99 & $\mathrm{~g}_{\mathrm{LA}} \mathrm{g}_{\mathrm{GL}}-1$ \\
\hline$\beta_{21}^{\prime}$ & & 0.67 & 0.67 & $\mathrm{~g}_{\mathrm{ACE}} \mathrm{g}_{\mathrm{GL}}{ }^{-1}$ \\
\hline$\beta_{22}^{\prime}$ & & 0.49 & 0.49 & $\mathrm{~g}_{\mathrm{CO} 2} \mathrm{~g}_{\mathrm{GL}}-1$ \\
\hline$\beta_{23}^{\prime}$ & & 0.44 & 0.44 & $\mathrm{~g}_{\mathrm{H} 2 \mathrm{O} 2} \mathrm{~g}_{\mathrm{GL}}{ }^{-1}$ \\
\hline$\beta_{51}^{\prime}$ & $27.02\left(\beta_{42}\right)$ & 27.02 & 27.02 & $\mathrm{~g}_{\mathrm{HA}} \mathrm{g}_{\mathrm{N}}^{-1}$ \\
\hline$\gamma^{\prime} 31$ & $8.8\left(\gamma_{21}\right)$ & 8.8 & 8.8 & $\mathrm{~g}_{\mathrm{Xa}} \mathrm{g}_{\mathrm{N}}^{-1}$ \\
\hline$\gamma^{\prime} 42$ & $0.98\left(\gamma_{32}\right)$ & 0.97 & 0.97 & $\mathrm{~g}_{\mathrm{xg}} \mathrm{gxa}^{-1}$ \\
\hline
\end{tabular}

$\mathrm{CO}_{2}$ to lactic acid (13\%) are as reported elsewhere (11) due to the augmentation of $\mathrm{HA}$ biosynthesis under aerated conditions. Similarly, the rate constant for HA production $\left(\mathrm{K}_{5}^{\prime}\right)$ was estimated by increasing its anaerobic counterpart by the same percentage $(20 \%)$; aerated growth has been observed to augment HA production (11). The rate constants for $X_{A}$ and $X_{G}$ formation in the aerobic model were assigned the same values as those used to model anaerobic growth despite the presence of growth inhibition, as the aerobic model requires their values to determine the upper limits of growth. Finally, the critical $\mathrm{H}_{2} \mathrm{O}_{2}$ concentration was taken to be the same $\left(0.17 \mathrm{~g} \mathrm{~L}^{-1}\right)$ as that found for the aerobic cultures of lactic acid-producing Lactobacillus species (28).

By the same approach used with the anaerobic model, the estimated model parameters were fine-tuned as necessary by comparison with aerated batch data (data not shown). The fitted parameters are tabulated in Table 8. N one of the aerobic stoichiometric coefficients required any modification except for $\alpha^{\prime}{ }_{61}$, which relates the grams of hydrogen peroxide produced per gram $\mathrm{X}_{\mathrm{A}}$ produced. This was not surprising, as the relatively high value obtained for $\alpha_{61}^{\prime}$ (1.474) suggests that inactivation of the $\mathrm{X}_{\mathrm{A}}$ component involves multiple binding of $\mathrm{H}_{2} \mathrm{O}_{2}$.

\section{Results and Discussion}

Model Verification. Anaerobic Growth. The anaerobic model was tested against experimental data; representative results are presented in Figures 1 and 2 . The 
Table 9. HA and Lactate Yields for S. Zooepidemicus under Conditions of Glucose and Complex-Nitrogen Limitationa

\begin{tabular}{|c|c|c|c|c|c|c|c|c|c|}
\hline growth conditions & $\begin{array}{c}X / G I \\
\left(g^{-1}\right)\end{array}$ & $\begin{array}{l}\mathrm{HA} / \mathrm{GI} \\
\left(\mathrm{g} \mathrm{g}^{-1}\right)\end{array}$ & $\begin{array}{l}\mathrm{HA} / \mathrm{X} \\
\left(\mathrm{g} \mathrm{g}^{-1}\right)\end{array}$ & $\begin{array}{l}\mathrm{LA} / \mathrm{GI} \\
\left(\mathrm{g} \mathrm{g}^{-1}\right)\end{array}$ & $\begin{array}{r}\mathrm{HA} / \mathrm{TN} \\
\left(\mathrm{g} \mathrm{g}^{-1}\right)\end{array}$ & $\begin{array}{c}\mathrm{MW} \\
\text { (MDa) }\end{array}$ & $\begin{array}{l}\mathrm{ET} / \mathrm{GI} \\
\left(\mathrm{g} \mathrm{g}^{-1}\right)\end{array}$ & $\begin{array}{c}\mathrm{FOR} / \mathrm{GI} \\
\left(\mathrm{g} \mathrm{g}^{-1}\right)\end{array}$ & $\begin{array}{c}\text { ACE/GI } \\
\left(\mathrm{g} \mathrm{g}^{-1}\right)\end{array}$ \\
\hline \multicolumn{10}{|c|}{ Anaerobic } \\
\hline batch: [5] & $0.125^{b}$ & 0.075 & $0.60^{\mathrm{b}}$ & 0.84 & $\mathrm{~nm}$ & 2.1 & $\mathrm{~nm}$ & $\mathrm{~nm}$ & $\mathrm{~nm}$ \\
\hline batch: [6] & $0.19^{b}$ & 0.076 & $0.4^{b}$ & 0.67 & $\mathrm{~nm}$ & $\mathrm{~nm}$ & $\mathrm{~nm}$ & $\mathrm{~nm}$ & $\mathrm{~nm}$ \\
\hline Figures $1 \& 2$ & 0.126 & 0.082 & 0.65 & 0.80 & 4.74 & 2.65 & $<0.005$ & $<0.005$ & $<0.005$ \\
\hline glucose-limited fed-batch: $\left(\mu>0.13 \mathrm{~h}^{-1}\right)$ & 0.083 & 0.075 & 0.90 & 0.63 & $\mathrm{~nm}$ & 1.8 & 0.07 & 0.13 & 0.09 \\
\hline nitrogen-limited fed-batch & 0.074 & 0.086 & 1.17 & 0.73 & 10.1 & 1.8 & 0.01 & 0.02 & 0.01 \\
\hline Fiqures $3-6$ & 0.10 & 0.096 & $\begin{array}{c}\text { Aerobic } \\
0.89\end{array}$ & 0.72 & $\mathrm{~nm}$ & $\mathrm{~nm}$ & $\mathrm{~nm}$ & $\mathrm{~nm}$ & $\mathrm{~nm}$ \\
\hline
\end{tabular}

a All data presented are for anaerobic fermentation cultivated under standard conditions [6]. Symbols: HA, hyaluronic acid; X, biomass; LA, lactic acid; GI, glucose; TN, total nitrogen; MW, molecular weight, ET; ethanol; FOR, formic acid; ACE, acetate. b Yields using biomass are questionable because cells were not stripped of HA capsule prior to OD or dry weight measurements.

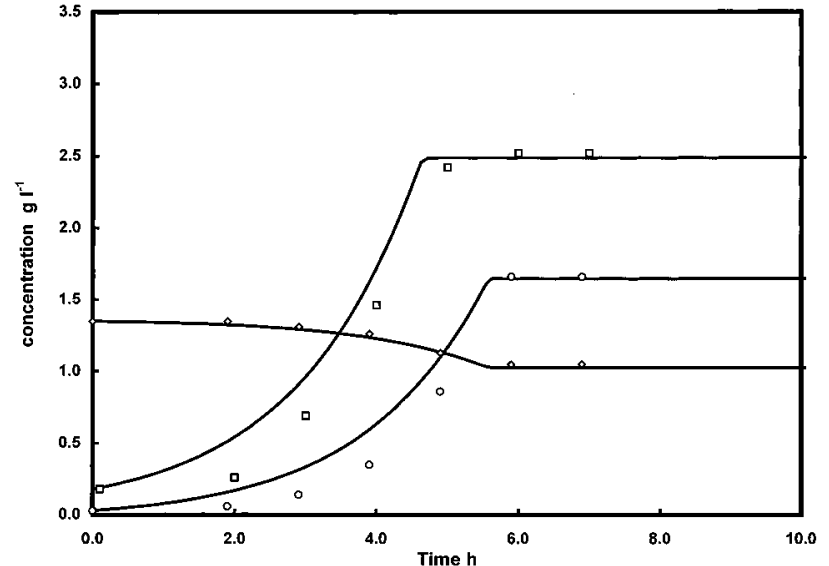

Figure 1. Anaerobic batch growth of $\mathrm{S}$. zooepidemicus in nonnutrient-limiting media. Symbols: solid lines, model simulations; open squares, bi omass; open circles, HA; open diamonds, total nitrogen.

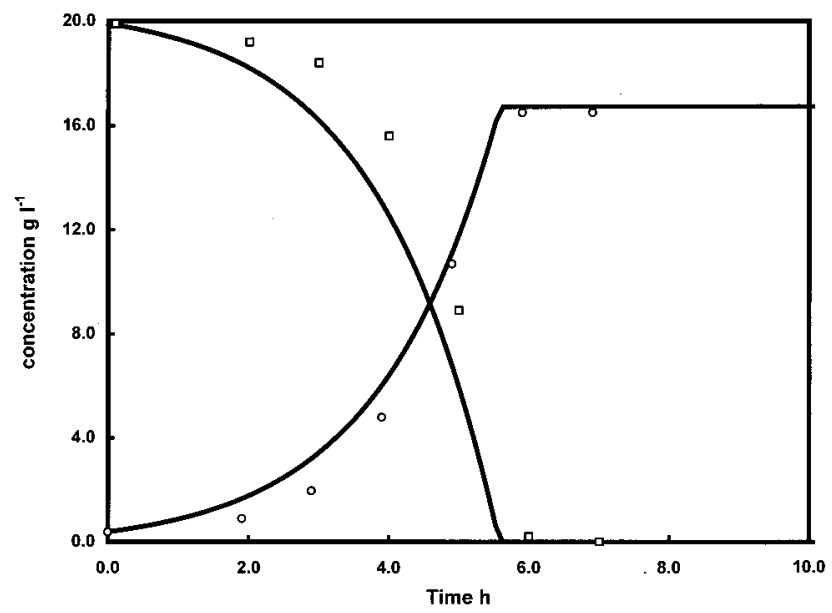

Figure 2. Anaerobic batch growth of $\mathrm{S}$. zooepidemicus in nonnutrient-limiting media. Symbols: solid lines, model simulations; open squares, glucose; open circles, lactate.

simulated profiles of the two-compartment model agree well with the experimental data, whereas the output of a simple Monod-type unstructured model (data not shown) failed to produce a satisfactory fit to experimental data, particularly during the transient phases of the run. The total nitrogen consumed $\left(0.34 \mathrm{~g} \mathrm{~L}^{-1}\right)$ amounts to a C-molar dry cell weight nitrogen composition of approximately $12 \%$, which is in reasonable agreement with reported estimates of nitrogen content found in biomass (31). More, the HA to glucose (HA/S) and biomass (HA/ $\mathrm{X})$ yields presented in Table 9 were found, where appropriate, to be similar to those reported by others under similar conditions $(5,32)$.

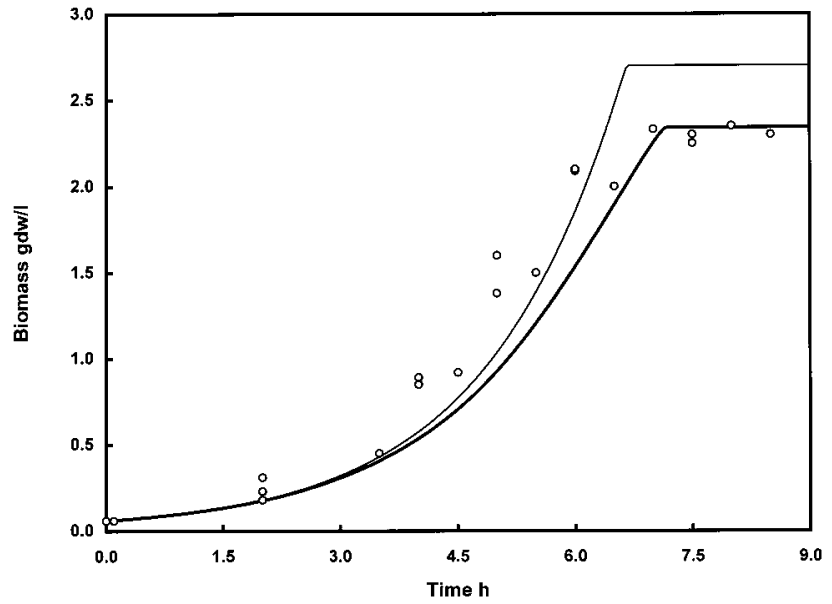

Figure 3. Aerobic batch growth of $\mathrm{S}$. zooepidemicus in nonnutrient-limiting media. Symbols: heavy dark line, model simulation with hydrogen peroxide inhibition; thin solid line, model simulation without inhibition; open circles, biomass.

In accordance with a higher value for the stoichiometric constant $\alpha_{21}$, a mass balance analyzing the distribution of total nitrogen and carbon from substrates to products, assuming that biomass comprises $50 \%$ carbon by weight, suggested that approximately $58 \%$ of the biomass carbon was derived from glucose, whereas the remaining carbon must have derived from the complex-nitrogen sources provided in yeast extract. It would appear, then, that our strain of Streptococcus zooepidemicus differs from other lactic acid bacteria in this respect, although more accurate data from techniques such as radioactive carbon tracing experiments are needed for a more definitive answer.

Aer obic Growth. The aerobic two-compartment model was verified against several sets of batch fermentation data. The results are provided in Figures 3-6. There was good agreement between the simulated profiles and the experimental data for both substrate consumption and product formation. The relatively higher values for dry weight measurements, however, suggests interference from the lingering presence of capsular $\mathrm{HA}$, which was insufficiently stripped from the cells prior to measurement. This difficulty is more pronounced with aerated cultures of S. zooepidemicus since cells under such conditions tend to possess very large capsules (11).

The excellent model agreement supports the suggestion that decreased biomass production under aerated conditions can be explained by assuming that the production of hydrogen peroxide binds irreversibly with the active components $\left(X_{A}\right)$ of the cells synthesis machinery. Mathematically, this can be equated to the transfer of the a percentage of the active compartment $\left(X_{A}\right)$ to the inactive compartment $\left(X_{G}\right)$ which serves to partially reduce the 


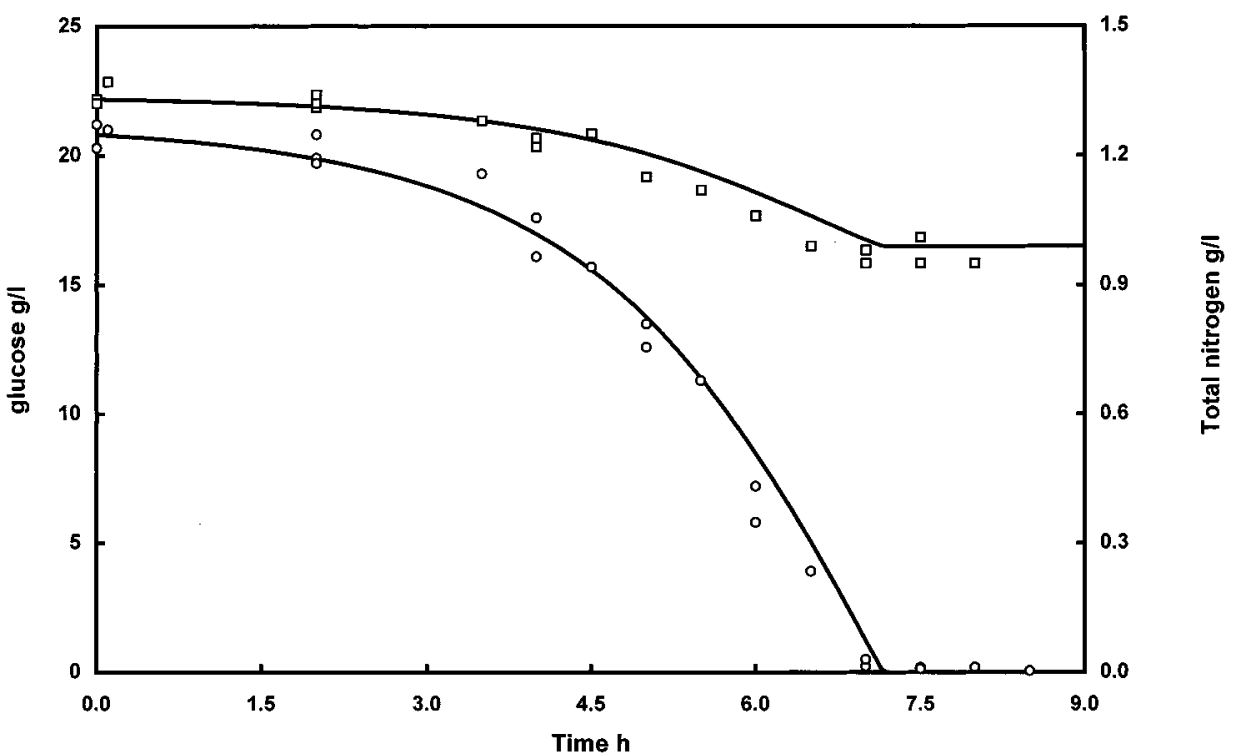

Figure 4. Aerobic batch growth of S. zooepidemicus in nonnutrient-limiting media. Symbols: heavy dark line, model simulation with hydrogen peroxide inhibition; open circles, glucose; open squares, total nitrogen.

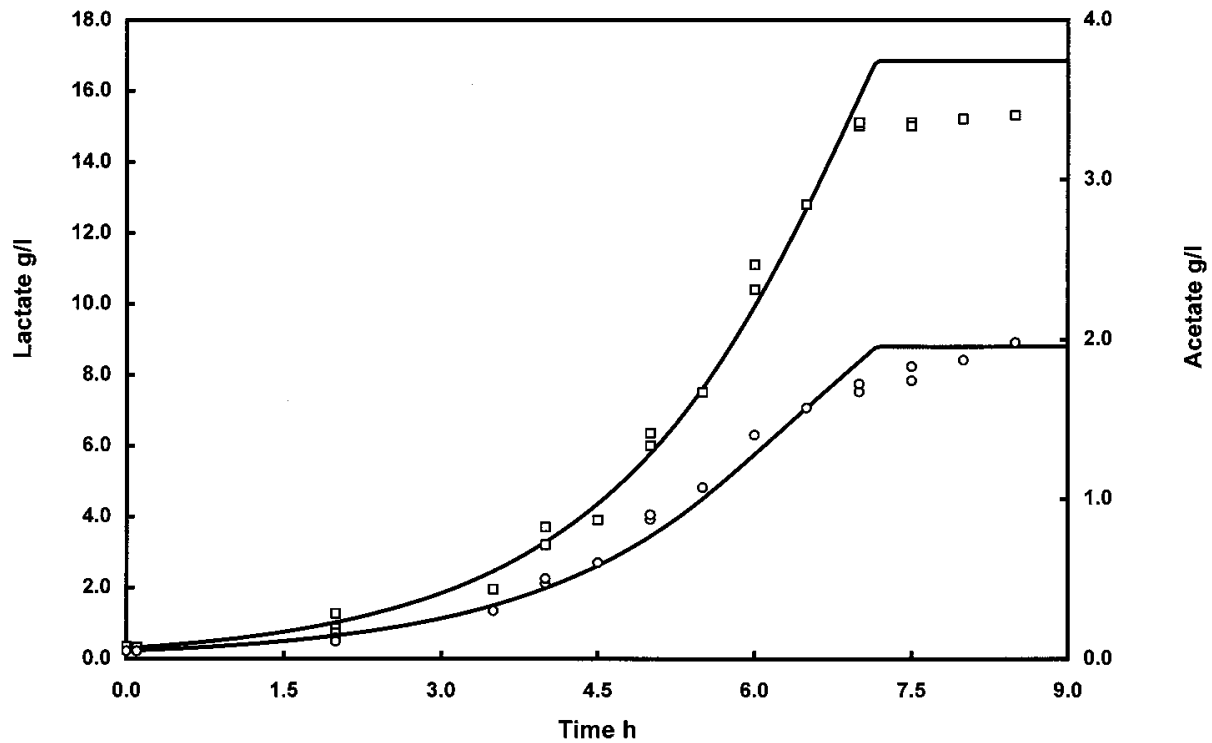

Figure 5. Aerobic batch growth of S. zooepidemicus in nonnutrient-limiting media. Symbols: heavy dark line, model simulation with inhibition; open circles, acetate; open squares, lactate.

reaction rates responsible for biomass production. Since growth and HA biosynthesis are two physiological processes competing for the same pool of cellular resources derived from glucose (e.g., $\mathrm{N}$-acetyl-glucosamine; required for cell wall synthesis and HA production), the reduction in growth rate permits a greater diversion of glucose toward the HA production pathway. Although both anaerobic and aerobic batch cultures of S. zooepidemi cus utilized the same relative amounts of glucose for energy metabolism, less lactate $\left(15 \mathrm{~g} \mathrm{~L}^{-1}\right)$ was produced compared to an equivalent anaerobic culture $\left(17 \mathrm{~g} \mathrm{~L}^{-1}\right)$.

Glucose-Limited Growth (Low C/N). Under certain environmental conditions, various Streptococci species have been reported to catabolize gl ucose using additional pathways (heterofermentative catabolism), which release a mixture of organic acids (predominantly formate, acetate) and ethanol, in addition to lactate (33). Under glucose-limiting conditions, lactic acid bacteria switch to heterofermentative glucose catabol ism to compensate for the reduced rate of cellular energy (ATP) production due to lower glucose uptake-that is, an additional mole of ATP is generated when glycolytic intermediate, pyruvate, is converted to acetate, instead of lactate (i.e., change stoichiometry when rate is diminished). Obviously, the other effect of glucose limitation is growth rate reduction, since the overall cellular energy output is lowered. Of particular interest here is the effect of reduced growth rate (due to glucose limitation) on HA production.

The glucose feed rate of the glucose-limited fed-batch experiment and the results are presented in Figures 7-10. The initial flow rate, $F_{0}$, was $0.004 \mathrm{~L} \mathrm{~h}^{-1}$ and the step increase, delayed by an additional $3.5 \mathrm{~h}$, was increased to a final steady-state value of $0.036 \mathrm{~L} \mathrm{~h}^{-1}$; the flow-rate was thereafter maintained at this level until a total of $0.3 \mathrm{~L}$ of sterile glucose solution (equivalent to 40 $\mathrm{g}$ of glucose) was added to the vessel. The fed-batch model was then resimulated and compared against the experimental data using the initial conditions presented in Table 1 with the following exceptions: $X_{0}=0.15 \mathrm{~g} \mathrm{~L}^{-1}$; $\mathrm{S}_{\mathrm{o}}=0.27 \mathrm{~g} \mathrm{~L}^{-1}$; $\mathrm{LA}_{\circ}=0.24 \mathrm{~g} \mathrm{~L}^{-1}$; and $\mathrm{HA}_{\circ}=0.0 \mathrm{~g} \mathrm{~L}^{-1}$; $\mathrm{S}_{\text {fo }} 136.0 \mathrm{~g} \mathrm{~L}^{-1}$; and $\mathrm{V}_{\mathrm{o}}=1.92 \mathrm{~L}$.

Figure 7 presents the biomass and HA profiles along with model simulations. While the HA profile matched model predictions, the model predicted biomass lagged 


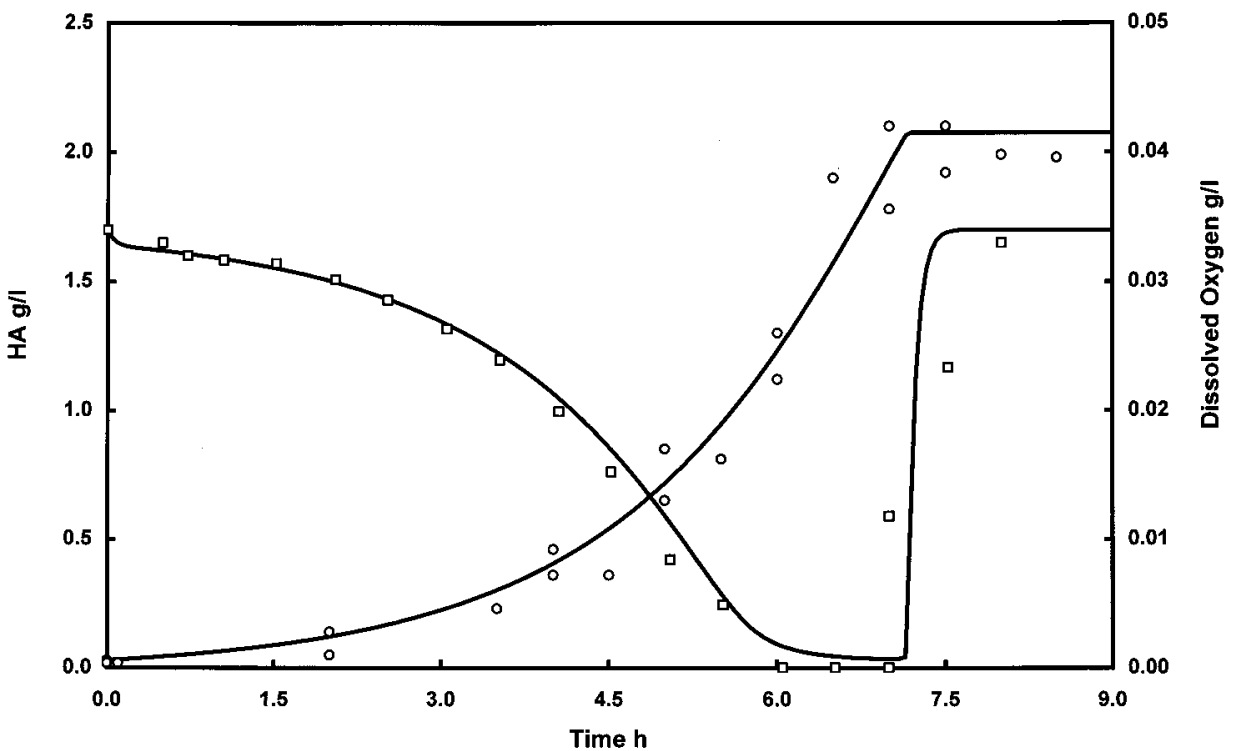

Figure 6. Aerobic batch growth of $S$. zooepidemicus in nonnutrient-limiting media. Symbols: heavy dark line, model simulation with inhibition; open circles, HA; open squares, dissolved oxygen.

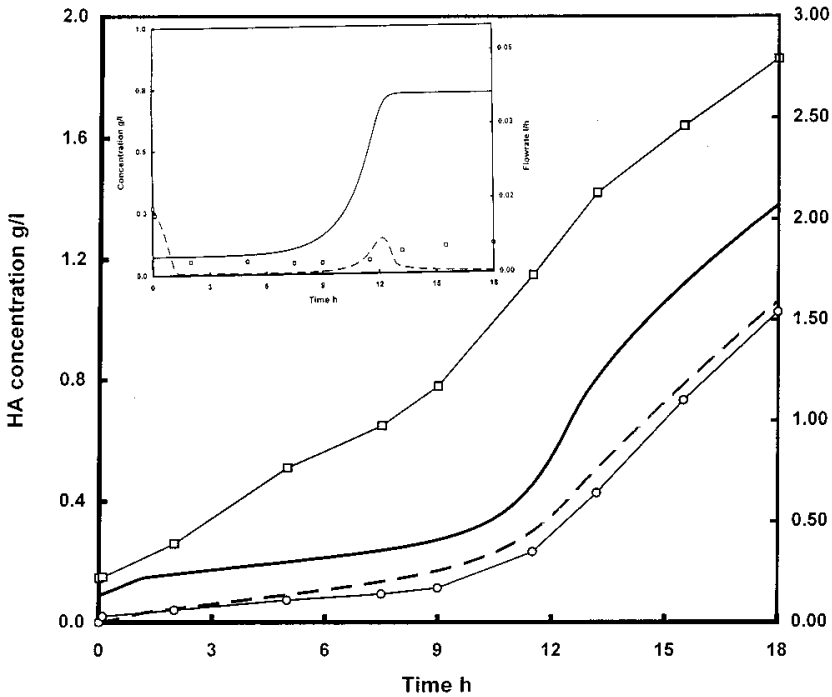

Figure 7. Glucose-limited anaerobic fed-batch fermentation of S. zooepi demicus. Symbols: dark smooth line, model prediction biomass; dark dashed line, model simulation HA; connected open squares, reactor biomass; connected open circles, reactor HA. Inset: smooth line, glucose feed rate; dashed line, model predicted reactor glucose concentration; open squares, reactor glucose concentration.

that of the experimental data until the step increase in substrate feed flow rate was imposed $(\approx 9 \mathrm{~h})$; thereafter the model profile, although delayed by several hours, trended the data. During the first $9 \mathrm{~h}$, the model deviated from the experimental data for biomass concentration because the model structure does not account for heterofermentative glucose catabolism, which facilitates better biomass growth due to stoichiometric increase in ATP production.

The simualted lactate profile deviated from the experimental data during the first $11.5 \mathrm{~h}$ of the fed-batch run (Figure 8), because glucose was catabolized under the heter ofermentative mode, end products lactate, acetate, formate, and ethanol (F igure 9), whereas the formulated model only simulates the homofermentative mode of glucose catabolism (Tables 2 and 3), hence the observed overprediction of lactate in the first $10 \mathrm{~h}$ (Figure 8). However, from the 11.5th hour onward, the model lactate

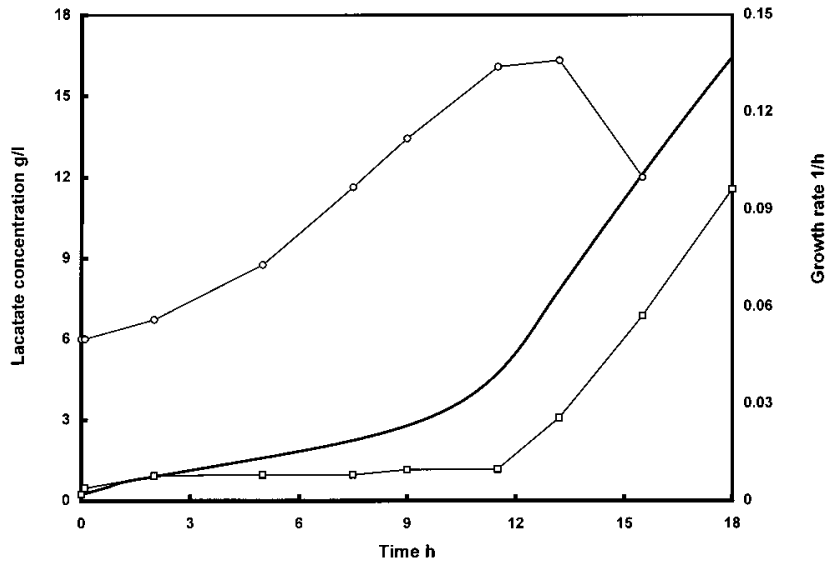

Figure 8. Anaerobic glucose-limited fed-batch fermentation of Streptococcus zooepi demicus. Symbols: dark smooth line, model simulation lactate; connected open squares, reactor lactate; connected open circles, growth rate.

profile trended the experimental data (i.e., same slope) because the model prediction was based on the same glucose catabolic pathway as the actual. Clearly, heterofermentative mode of glucose catabolism occurred when the medium glucose concentration was below $0.1 \mathrm{~g} \mathrm{~L}^{-1}$ (F igure 7; inset). The relative fluxes of the catabolic end products are shown in Figure 9 (inset).

By contrast, the HA profile agreed well with model predictions (Figure 7). As the model was originally formulated to simulate anaerobic homofermentative growth in the presence of excess glucose and complexnitrogen, this agreement indicates glucose-limited growth; whether the mode of glucose catabolism was hetero- or homofermentative had little effect on the volumetric production of $\mathrm{HA}$. It is perhaps enlightening to consider this result with regard to overall $\mathrm{HA}$ yields compared to that found for cultivation in standard batch culture (Table 9). Clearly, the similar HA yields on glucose between the batch and glucose-limited fed-batch cultures imply that the overall glucose distribution to HA biosynthesis pathway (stoichiometry) in S. zooepidemi cus was relatively constant despite the differences in cultivation mode, growth rate, and catabolic pathways. It should also be noted that the measured weight-average HA molecular weight (1.8 MDa) was lower than expected (2.2 MDa) 


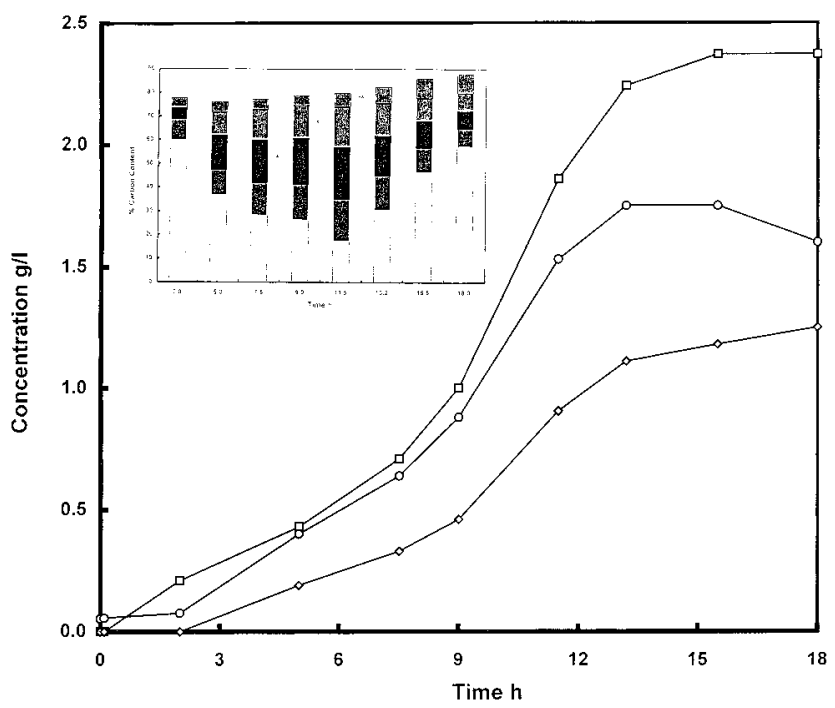

Figure 9. Anaerobic glucose-limited fed-batch fermentation of Streptococcus zooepidemicus. Symbols: connected open squares, formate; connected open circles, acetate; connected open diamonds, ethanol. Inset: Percentage relative to total carbon (biomass assumed to be $50 \%$ ) of carbon end products. Bottom (clear) is lactate (L) followed by formate $(F)$, acetate $(A)$, ethanol $(\mathrm{E})$, and finally hyaluronic acid (HA).

(14). A likely explanation for this is that it is due to the imposed glucose limitation in the fed-batch culture, which lowered the specific glucose uptake rate of the microorganism; as a result, the pool of HA precursors (Dglucuronate and $\mathrm{N}$-acetyl-glucosamine) formed over a certain time period would be smaller, and presumably, if the mean life span of the membrane-bound polymerizing enzyme, hyaluronate synthase, was the same (as expectedly) in both cases, shorter HA chains would be produced.

Complex-Nitrogen-Limited Growth (High C/N). The HA fermentation has traditionally been cultivated in excess complex-nitrogen substrate (yeast extract), as very little literature has addressed the fastidious nitrogen requirement of S. zooepidemicus; that literature which does exist has focused on the development of defined media which are less efficient (4). Initial attempts to study the effect of complex-nitrogen limitation (using yeast extract) on HA production as well as cell physiology were interrupted by the occurrence of transitional growth phases (i.e., diauxic growth) in batch culture; S. zooepidemicus presumably demonstrated preferential utilization of nitrogen substrate in yeast extract, since it switched from one pool of nitrogen substrate to another, upon exhaustion of the previous pool. Alternatively, the fed-batch cultivation technique can be used to limit the first pool nitrogen substrate of yeast extract in the medium, by controlling the feeding rate of yeast extract. A feed-back control loop, presented in Figure 10 and detailed in Appendix A, was then implemented to modify, as needed, the feed rate of yeast extract added to the reactor (34). The biomass profile was selected as the most suitable control variable, since transient parameter sensitivity analysis revealed the biomass profile to be relatively the most sensitive variable to a disturbance in those parameters reflecting a change in nitrogen consumption (15).

The results are presented in Figure 11. As the biomass concentration lagged that predicted by the model, the control algorithm was initiated after $4 \mathrm{~h}$. In time, the control algorithm had increased the flow rate until the corrections had deviated unacceptably far from the

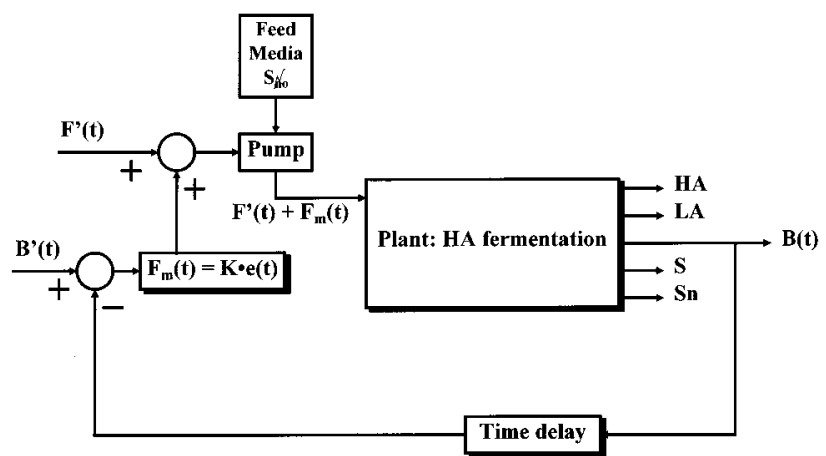

Figure 10. Process diagram for feedback control of nitrogenlimited, fed-batch cultivation of S. zooepi demicus. Symbols: HA$(\mathrm{t}), \mathrm{LA}(\mathrm{t}), \mathrm{B}(\mathrm{t}), \mathrm{S}(\mathrm{t})$, and $\mathrm{S}_{\mathrm{n}}(\mathrm{t})$, reactor profiles of hyaluronic acid: lactic acid, biomass, glucose, and total nitrogen in fed-batch culture; $F^{\prime}(t)$, feed rate profile of nitrogen substrate; $B^{\prime}(t)$, model simulation; $F_{m}(t)$, controller calculated correction term in feed rate of nitrogen substrate; $K$, controller gain which represents eqs 1 and 2 . The time delay represents sampling time of every 15-30 min.

original feed substrate profile. Clearly, little if any success was achieved as the accumulative changes in the feed flow rate were not able to compensate for deviations from model predictions.

An explanation was found in the fact that the set-point biomass profile was generated with model simulations that assume $S$. zooepidemicus can consume the complexnitrogen provided in the feed stream devoid of any effects (i.e., indistinguishable of the nitrogen substrate pools). In other words, the entire complex-nitrogen feed was regarded as a homogeneous source of nitrogen. Obviously, this assumption does not hold, particularly in light of the diauxic growth results, but in reality, there is little al ternative: the model without a detailed analysis of the nitrogen requirements of $\mathrm{S}$. zooepidemicus, coupled with a lack of identification of the constituent components of yeast extract cannot be expected to account for the various transitions in growth due to preferred uptake of various nitrogen components contained within the yeast extract.

To resol ve this problem, we performed complex-nitrogenlimited batch experiments (data not shown) to quantify the size of preferred pool of nitrogen substrate in yeast extract by S. zooepidemicus, 38\% (w/w) of the total yeast extract nitrogen. On the basis of that, the feed nitrogen substrate concentration $\left(\mathrm{S}_{\mathrm{Nf}}\right)$ was increased by approximately a factor of 2.5 (or roughly the inverse of $38 \%$ ). In the actual experiment performed, the feed concentration of total nitrogen was $5.0 \mathrm{~g} \mathrm{~L}^{-1}$ (i.e., the yeast extract concentration was raised from 23.3 to $50.0 \mathrm{~g} \mathrm{~L}^{-1}$ ).

The resulting control experiment, in which the control algorithm was implemented after $2 \mathrm{~h}$, is presented in Figure 12. Initially, the biomass profile lagged that predicted by the optimal solution, but this was largely due to the fact that the inoculum concentration was much lower than that used in the original simulation $(0.03$ versus $0.16 \mathrm{~g} \mathrm{~L}^{-1}$ ). Nevertheless, the biomass concentration did slightly lag the set-point profile until by $8 \mathrm{~h}$ the biomass profile $(\mathrm{B}(\mathrm{t}))$ was corrected to match that of the set-point profile $\left(B^{\prime}(t)\right)$. It can also be seen from Figure 12 that the corrections to the flow rate were not overly dramatic and, in fact, had to be reduced after $8 \mathrm{~h}$ to correct for overshoot.

Most interesting to observe is how well the model predicted the transient profiles in the remaining state variables. Figures 13 and 14 present model predictions against experimental data after the model was resimu- 


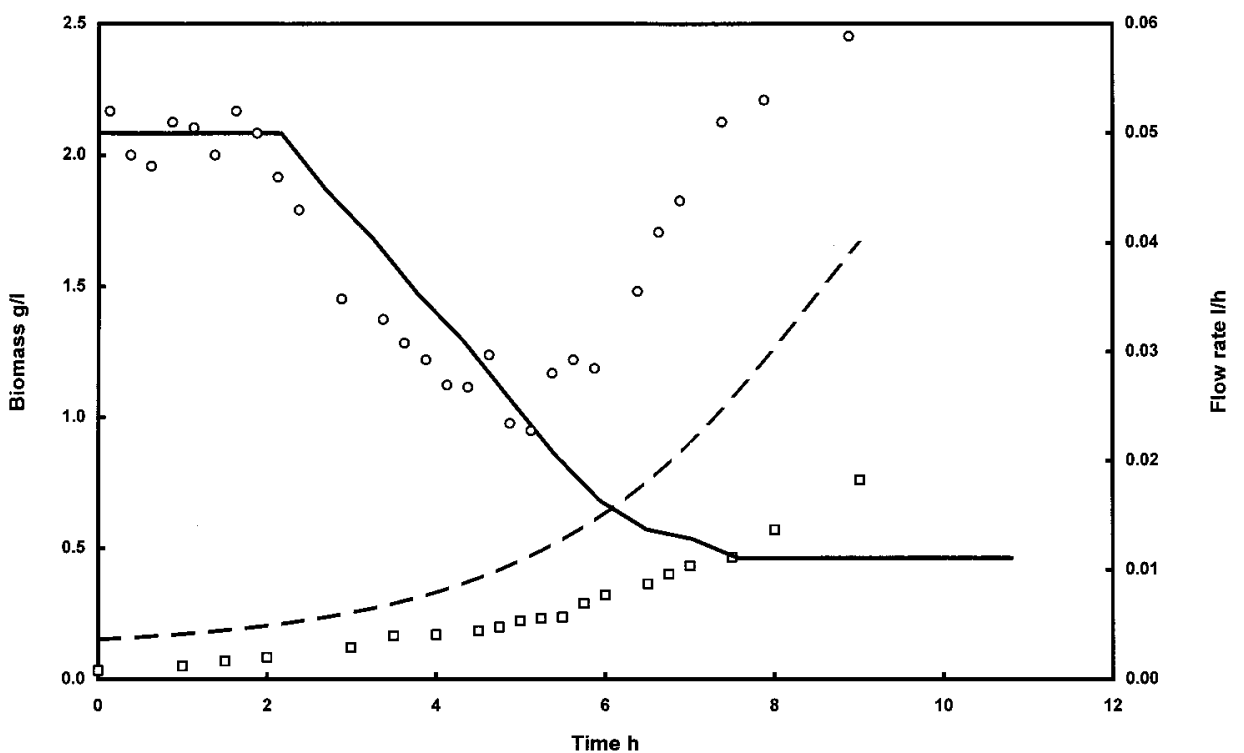

Figure 11. Feedback control of nitrogen-limited fed-batch culture of S. zooepidemicus. Symbols: Solid line, feed rate of nitrogen substrate, $F^{\prime}(t)$; dashed line, model simulation of biomass profile $\left(B^{\prime}(t)\right)$; open circles, controller corrected feed rate, $F_{m}(t)+F^{\prime}(t)$; open squares, experimental biomass concentration $(B(t))$.

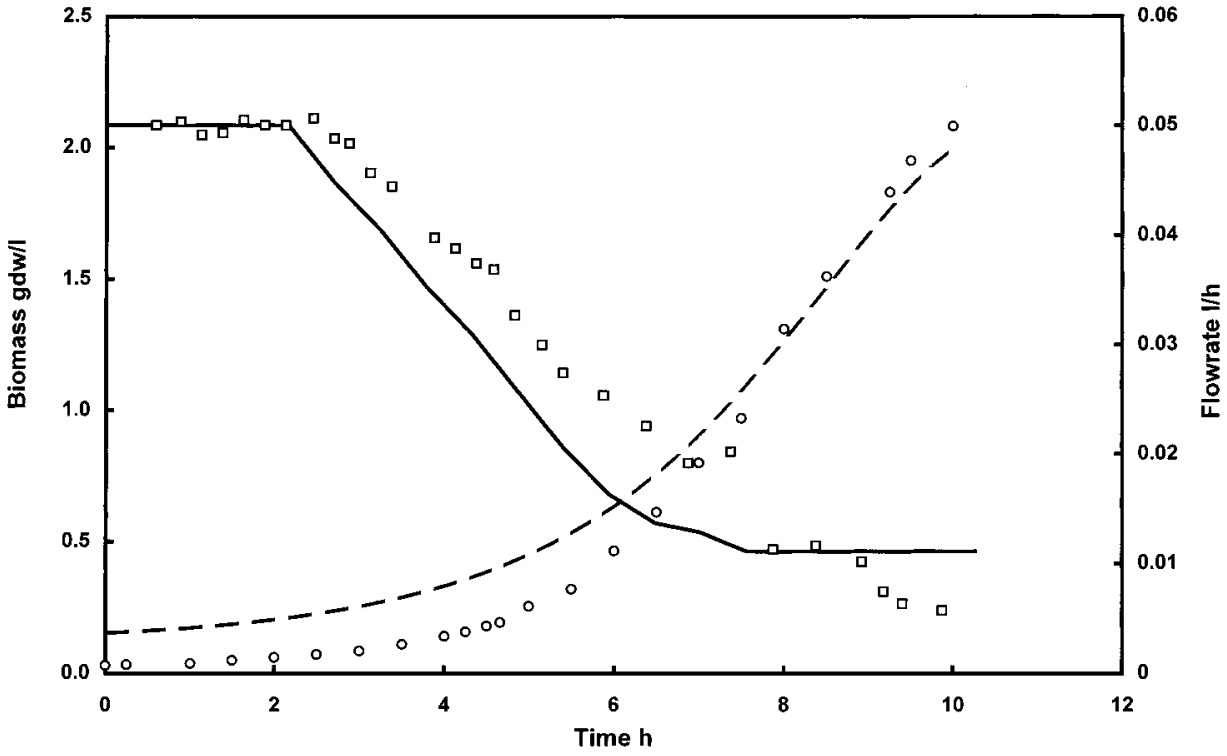

Figure 12. Feedback control of nitrogen-limited fed-batch culture of S. zooepidemicus. Symbols: Solid line, feed rate of nitrogen substrate, $F^{\prime}(t)$; dashed line, model set-point biomass profile $\left(B^{\prime}(t)\right)$; open circles, controller corrected feed rate, $F_{m}(t)+F^{\prime}(t)$; open squares, experimental biomass concentration $(B(t))$.

lated to account for the measured flow rate of nitrogen substrate, the increased feed substrate concentration (5.0 $g_{T N} L^{-1}$ ), and the volume loss due to sampling. The initial conditions used to simulate the model were as presented in Table 1 except for the following changes: $\left(\mathrm{g} \mathrm{L}^{-1}\right) \mathrm{X}_{\text {to }}$ $=0.03, \mathrm{~S}_{\mathrm{o}}=41.2, \mathrm{~S}_{\mathrm{No}}=0.014, \mathrm{~L}_{\mathrm{Ao}}=0.07, \mathrm{H}_{\mathrm{Ao}}=0.0$; and $(\mathrm{L}) \mathrm{V}_{\mathrm{o}}=1.7$. At first try, all state variables except the HA profile foll owed the experimental data extremely well. To predict the HA profile, however, we had to increase the rate constant $\mathrm{k}_{4}$ from 0.046 to $0.073 \mathrm{~h}^{-1}$ (see Tables 2 and 4). The simulation presented in Figures 13 and 14 uses this value of $k_{4}$. As such, to predict complexnitrogen-limited growth, the HA model developed in nonnutrient-limited batch culture required only the modification of a single rate constant, that being the one that controls the rate of HA production. Hence, the rate of HA production is greater under conditions of complexnitrogen-limited growth as opposed to nonnutrientlimited growth. It is also worth noting that a consequence of this phenomena is that the HA to total nitrogen yield was twice that found in typical batch nonnutrient-limited growth (see Table 9).

The presence of mixed organic acids and ethanol (see Table 8) was al so observed but only in low concentrations. The initiation of their production, however, varied; acetate and ethanol production was present from the outset while formate production was present after $6 \mathrm{~h}$ of effective fermentation time (data not shown). Like that found for glucose-limited growth, the resulting molecular weight of the HA produced (1.8 MDa) was less than that observed in typical anaerobic batch cultures or for that observed under conditions of temperature-induced low growth rates (14). The results suggest that the failure to augment HA yield and molecular weight by reducing growth through complex-nitrogen substrate limitation is probably due to the nonspecificity of the substrate limitation, since an important requirement of HA biosynthesis is gl utamine (i.e., needed to produce one of the 


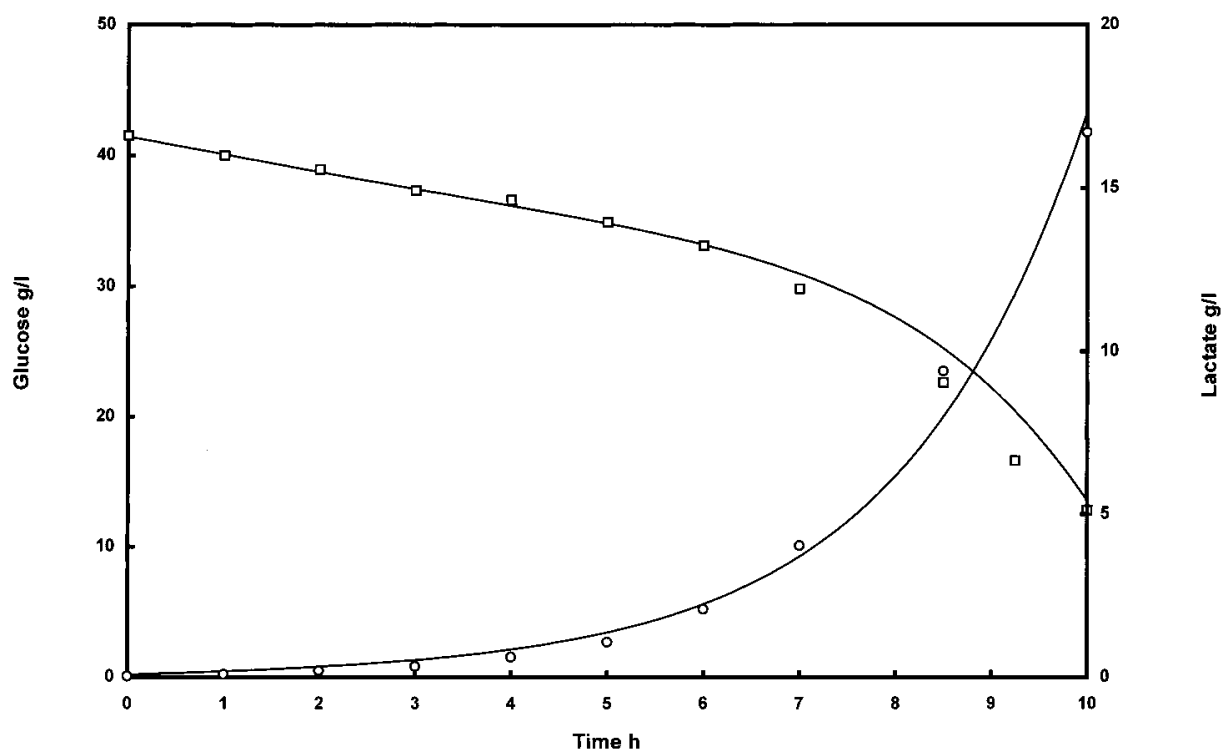

Figure 13. Model verification of nitrogen-limited anaerobic fed-batch culture of S. zooepidemicus $\left(\mathrm{k}_{4}=0.073 \mathrm{~h}^{-1}\right)$. Symbols: Solid lines, model simulations; open squares, reactor glucose; open cirdes, reactor lactate.

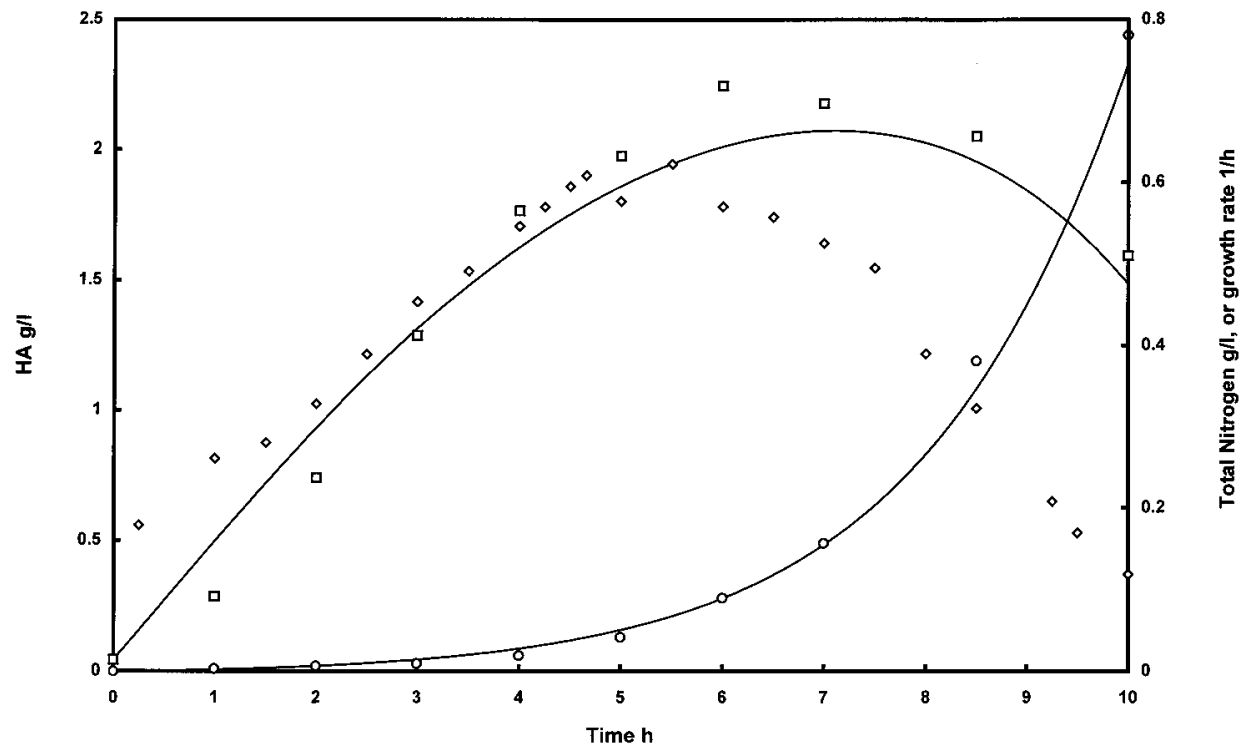

Figure 14. Model verification of nitrogen-limited fed-batch culture of $S$. zooepidemicus $\left(k_{4}=0.073 \mathrm{~h}^{-1}\right)$. Symbols: Solid lines, model simulations; open squares, total nitrogen; open circles, hyaluronic acid; open diamonds, growth rate (calculated from biomass).

two HA precursors, $\mathrm{N}$-acetyl-glucosamine), an amino acid present in yeast extract that is also required for growth. This conclusion is to be verified in future work.

\section{Appendix A}

The set-point biomass profile was generated by simulating the anaerobic model using the preproposed feed rate of complex-nitrogen. As the purpose of the control loop was to add or subtract from a pre-existing feed rate, integral action in the controller was not considered necessary. Therefore, a proportional gain was developed that converts a measured error (in biomass) to the amount of nitrogen that must be added to the reactor to correct the error:

$$
\mathrm{N}^{\prime}=\Delta \mathrm{BV} \mu \mathrm{Y}_{\mathrm{N} / \mathrm{X}}
$$

where $\mathrm{N}^{\prime}$ is the required change in the rate of nitrogen addition $\left(g_{N} h^{-1}\right), \Delta B$ is the measured error $\left(B^{\prime}(t)-B(t)\right)$ in biomass ( $\left.g d w \mathrm{~L}^{-1}\right), \mathrm{V}(\mathrm{t})$ is the transient fermenter volume (liters), $\mu$ is the transient growth rate $\left(\mathrm{h}^{-1}\right)$, and
$\mathrm{Y}_{\mathrm{N} / \mathrm{X}}$ is a yield factor consi dered constant and taken to be the inverse of the biomass yield on total nitrogen $\left(g_{\mathrm{N}}\right.$ $\mathrm{gdw}^{-1}$ ). It's value was calculated to be $0.128 \mathrm{gN}_{\mathrm{Ndw}}^{-1}$ using the batch data presented in our first paper as follows: on average $2.5 \mathrm{gdw} \mathrm{L}^{-1}$ of biomass is produced per $0.32 \mathrm{~g} \mathrm{~L}^{-1}$ total nitrogen consumed. If the transient growth rate $\mu(\mathrm{t})$ and reactor volume $\mathrm{V}(\mathrm{t})$ cannot be determined on-line, there their values can be approximated from the model simulations.

The conversion from $\mathrm{N}^{\prime}$ to the required change in flow rate of feed nitrogen $\left(F_{m}(t)\right)$ can be calculated as follows:

$$
F_{m}(t)=\frac{100}{K} N^{\prime}(t)
$$

where $\mathrm{K}$ is a factor, assumed linear, that gives the mass flow rate of nitrogen $\left(g_{N} h^{-1}\right)$ when the pump is set at $100 \%$. It was calculated by setting the feed pump to $100 \%$ and multiplying the measured flow rate (on average $\left.0.0708 \mathrm{~L} \mathrm{~h}^{-1}\right)$ by the feed nitrogen concentration $(2.33$ $\left.g_{N} L^{-1}\right)$. 


\section{Acknowledgment}

Funding from the Australian Research Council (Large Grant A89531789) is gratefully acknowledged by the authors. The contribution of Dr. Andreas Oeggerli, who developed the computer code integrating the HA model equations, is gratefully acknowledged. Mr. Peter Abeydeera and Dr. Beatrice Keller are thanked for their assistance with HPLC and total nitrogen analysis of fermentation samples. The many helpful suggestions from Dave Armstrong were greatly appreciated.

\section{Notation}

D dilution rate $\left(\mathrm{h}^{-1}\right)$

S extracellular concentration of glucose $\left(g_{\mathrm{GL}} \mathrm{L}^{-1}\right)$

$\mathrm{S}_{\mathrm{N}} \quad$ extracellular concentration of total nitrogen

$\left(g_{T N} L^{-1}\right)$

LA extracellular lactic acid concentration $\left(g_{L A} L^{-1}\right)$

HA extracellular hyaluronic acid concentration

$\left(\mathrm{g}_{\mathrm{HA}} \mathrm{L}^{-1}\right)$

$X_{A} \quad$ active compartment ratio ( $\left.g_{x_{a}}{g d w^{-1}}\right)$

$X_{G} \quad$ genetic compartment ratio $\left(g_{x_{g}} g_{d w^{-1}}\right)$

$\mu \quad$ growth rate $\left(\mathrm{h}^{-1}\right)$

$r_{1} \quad$ intracellular reaction rate for LA synthesis

$\left(g_{G L} g d w^{-1} h^{-1}\right.$ )

$r_{2}$ intracellular reaction rate for $X_{A}$ synthesis

$\left(g_{\mathrm{TN}} \mathrm{gdw}^{-1} \mathrm{~h}^{-1}\right.$ )

$r_{3} \quad$ intracellular reaction rate for $X_{G}$ synthesis

$\left(g_{x a} g d w^{-1} h^{-1}\right)$

$r_{4} \quad$ intracellular reaction rate for HA synthesis

$\left(g_{\mathrm{N}} \mathrm{gdw}^{-1} \mathrm{~h}^{-1}\right.$ )

$k_{1} \quad$ kinetic rate constant for LA ( $\left.g_{G L} g_{X_{a}} h^{-1}\right)$

$k_{2} \quad$ kinetic rate constant for $X_{A}$ formation $\left(g_{T_{N}} g_{x_{a}} h^{-1}\right)$

$k_{3} \quad$ kinetic rate constant for $X_{G}$ formation $\left(g_{x_{a}} g_{x_{a}} h^{-1}\right)$

$\mathrm{k}_{4} \quad$ kinetic rate constant for HA formation ( $g_{\mathrm{TN}} \mathrm{g}_{\mathrm{xa}} \mathrm{h}^{-1}$ )

$\mathrm{KS}_{1-4}$ saturation constants for glucose substrate $\left(\mathrm{g} \mathrm{L}^{-1}\right)$

$\mathrm{Ksn}_{2-4}$ saturation constants for nitrogen substrate $\left(\mathrm{g} \mathrm{L}^{-1}\right)$

$\beta_{\mathrm{ij}} \quad$ product stoichiometric coefficients $\left(\mathrm{g} \mathrm{g}^{-1}\right)$

$\alpha_{i j} \quad$ substrate stoichiometric coefficients $\left(\mathrm{g} \mathrm{g}^{-1}\right)$

$\gamma_{\mathrm{ij}} \quad$ biotic phase stoichiometric coefficients $\left(\mathrm{g} \mathrm{g}^{-1}\right)$

Additional Terms for Aerobic Model

$\mathrm{H}_{2} \mathrm{O}_{2}$ extracellular hydrogen peroxide concentration $\left(\mathrm{g} \mathrm{L}^{-1}\right)$

ACE extracellular acetate concentration $\left(\mathrm{g} \mathrm{L}^{-1}\right)$

$\mathrm{CO}_{2}$ extracellular carbon dioxide concentration $\left(\mathrm{g} \mathrm{L}^{-1}\right)$

$\mathrm{K}_{\mathrm{L}} \mathrm{a}$ mass transfer coefficient for oxygen $\left(\mathrm{h}^{-1}\right)$

So dissolved oxygen $\left(\mathrm{g} \mathrm{L}^{-1}\right)$

\section{References and Notes}

(1) Swann, D. A.; Kuo, J .-W. Hyaluronic Acid. In Nove Materials from Biological Sources; Byron, D., Ed.; Stockton Press: New York, 1991; pp 287-305.

(2) Lerner, M. Hyaluronic acid market benefits from new uses. Chem. Mark. Rep. 1997, 250, 12-13.

(3) O'Regan, M.; Martini, I.; Crescenzi, F.; De Luca, C.; Lansing, M. Molecular Mechanisms and genetics of Hyaluron Biosynthesis. Int. J . Macromolecules 1994, 16, 283-286.

(4) Armstrong, D. L.; Cooney, M. J .; J ohns, M. R. Growth and amino acid requirements of hyaluronic acid-producing Streptococcus zooepi demicus. Appl. Microbiol. Biotechnol. 1997, 47, 309-312.

(5) Armstrong, D. C.; J ohns, M. R. Effect of Culture Conditions on Molecular Weight of Hyaluronic Acid Produced by Streptococcus Zooepidemicus. Appl. Environ. Microbiol. 1997, 63, 2759-2764.
(6) J ohns, M. R.; G. L.-T; Oeggerli, A. A. Effect of pH, agitation and aeration on HA production by Streptococcus zooepidemicus. Biotechnol. Lett. 1994, 15, 507-512.

(7) Lertwerawat, Y. Hyaluronic acid production and its instability in Streptococcus zooepidemicus. In Chemical Engineering: Brisbane: University of Queensland, 1993.

(8) Esener, A. A.; Veerman, T.; Roels, J . A.; Kossen, N. W. F. Modelling of Bacterial Growth; Formulation and Evaluation of a Structured Model. Biotechnol. Bi oeng. 1982, 23, 1749.

(9) Williams, F. M. A Model of Cell Growth Dynamics. J . Theor. Biol. 1967, 15, 190.

(10) Nielsen, J .; Nikolajsen, K.; Villadsen, J . Structured Modelling of a Microbial System: A Theoretical Study of Lactic Acid Fermentation, I. Bi otechnol. Bioeng. 1991, 38, 1-10.

(11) Goh, L.-T. Fermentation studies of hyaluronic acid fermentation by Streptococcus zooepidemicus. In Chemical Engineering; Brisbane: University of Queensland, 1998.

(12) Cameron, I. T. Solution of Differential and Algebraic Equations using Diagonally I mplicit Runge-Kutta Methods. IMA J. Numer. Anal. 1983, 3, 273-289.

(13) Nielsen, J .; Nikolajsen, K.; Villadsen, J . Structured Modelling of a Microbial System: II. Experimental Verification of a Structured Lactic Acid Fermentation Model. Biotechnol. Bioeng. 1991, 38, 11-23.

(14) Armstrong, D. The Effect of Growth Conditions on the Molecular Weight of Hyaluronic Acid Synthesised by Streptococcus zooepdemicus In Chemical Enginering; Brisbane: University of Queensland, 1997.

(15) Cooney, M. J .; Murray, J .; Lee, P. L.; J ohns, M. R. The Importance of Differential Sensitivity Analysis in the Modeling, Optimization, and Control of Fermentation Processes, presented at 7th International Conference on Computer Applications in Biotechnology, Osaka, J apan, 1998.

(16) Condon, S. Responses of lactic acid bacteria to oxygen. FEMS Microbiol. Rev. 1987, 46, 269-280.

(17) Zitzelsberger, W.; Götz, F.; Schleifer, K. H. Distribution of superoxide dismutases, oxidases, and NADH peroxidase in various streptococci; 1984, Vol. 21, pp 243-246.

(18) Higuchi, M.; Shimada, M.; Yamamoto, Y.; Hayashi, T.; Koga, T.; Kamio, Y. Identification of two distinct NADH oxidases corresponding to $\mathrm{H}_{2} \mathrm{O}_{2}$-forming oxidase and $\mathrm{H}_{2} \mathrm{O}$ forming oxidase induced in Streptococcus mutans," J . Gen. Microbiol. 1993, 139, 2343-2351.

(19) Abbe, K.; Takahashi, S.; Yamada, T. I nvolved of oxygensensitive pyruvate formatelyase in mixed acid fermentation by Streptococcus mutans under strictly anaerobic conditions; 1982, Vol. 152, pp 175-182.

(20) Kandler, O. Carbohyrate metabolism in lactic acid bacteria. Antonie van Leeuwenhoek 1983, 49, 209-224.

(21) Farrow, J . A. E.; Collins, M. D. Taxanomic studies on streptococci of serological groups $C, G$ and $L$ and possibly related taxa. Syst. Appl. Microbiol. 1984, 5, 483-493.

(22) Hardie, J. M. Genus Streptococcus. In Bergey's manual of determinative bacteriology; Sneath, P. H. A., Mair, N. S., Sharpe, M. E., Eds.; Williams and Wilkins: Baltimore, MD, 1986; Vol. 2, pp 1043-1071.

(23) Carlsson, J.; I wami, Y.; Yamada, T. Hydrogen peroxide excretion by oral streptococci and the effect of lactoperoxi dase thi ocyanite-hydrogen peroxide; 1983, Vol. 40, pp 70-80.

(24) Dugiseppin, J.; Fridovich, I. Oxygen toxicity in Streptococcus sanguis: the relative importance of superoxide and hydroxyl radicals; 1982, Vol. 257, pp 4046-4051.

(25) Fridovich, I. The bi ol ogy of oxygen radicals; 1990, Vol. 201, pp 875-880.

(26) Higuchi, M. Reduced nicotinamide adenine dinucleotide oxidase involvement in defense against oxygen toxicity of Streptococcus mutans; 1992, Vol. 7, pp 309-314.

(27) Rodriguez, A. V.; Manca de Nadra, M. C. Production of hydrogen peroxide by Lactobacillus hilgardii and its effect on Leuconostoc oenos growth. Curr. Mi crobiol. 1995, 30, 2325

(28) Sakamoto, M.; Komagata, K. Aerobic growth of and activities of NADH oxidase and NADH peroxidase in lactic acid bacteria. J . Ferment. Bioeng. 1996, 82, 210-216. 
(29) Levenspiel, O. The monod equation: A revisit and a generalisation to product inhibition situations; 1980, Vol. 22, pp 1671-1687.

(30) Nielsen, J .; Villadsen, J . Bioreaction Engineering Principles; Plenum Press: New York, 1994.

(31) Shuler, M. L.; Kargi, F. Bioprocess Engineering, 1st ed.; Prentice Hall: Englewood Cliffs, 1992.

(32) Goh, L.-T.; J ohns, M. R. Factors influencing the capsule size of Streptococcus zooepidemicus during hyaluronic acid synthesis. Enzyme Microb. Technol. Submitted for publication.
(33) Thomas, T. D.; Ellwood, D. C.; Longyear, V. M. C. Change from homo-to-heterolactic fermentation by Streptococcus lactis resulting from glucose limitation in anaerobic chemostat cultures. Bacteriology 1979, 138, 109.

(34) Hilaly, A. K.; Karim, M. N.; Guyre, D. Biotechnol. Bioeng. 1994, 43, 314-320.

Accepted May 28, 1999.

BP990078N 